NISTIR 88-3099

\title{
FRACTURE BEHAVIOR OF A PRESSURE VESSEL STEEL IN THE DUCTILE-TO-BRITTLE TRANSITION REGION
}

Jürgen Heerens

D.T. Read

National Institute of Standards and Technology

(formerly National Bureau of Standards)

U.S. Department of Commerce

Boulder, Colorado 80303-3328

December 1988

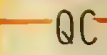

100

.456

88-3099

1988

C.2

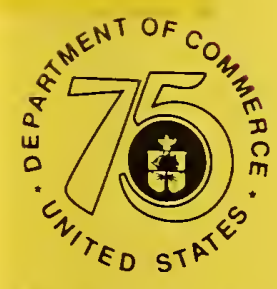


NATIONAL INSTITTE OF STANDARDS \&

TECKNOLOGY

Research information Center

Gaithersburg, MD 20899 
Jürgen Heerens*

D.T. Read

Fracture and Deformation Division

Institute for Materials Science and Engineering

National Institute of Standards and Technology

Boulder, Colorado 80303-3328

*GKSS Research Center

Geesthacht, West Germany

December 1988

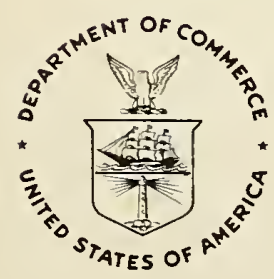

U.S. DEPARTMENT OF COMMERCE, C. William Verity, Secretary Ernest Ambler, Acting Under Secretary for Technology 



\section{CONTENTS}

1. INTRODUCTION

2. MATERIAL . . . . . . . . . . . . . . . . . . 2

3. EXPERIMENTAL DETAILS . . . . . . . . . . . . . . . 4

4. RESUlTS . . . . . . . . . . . . . . . . . . . . . . 4

4.1 Fracture Behavior of the Various Specimens . . . . . . . . . . 4

4.1 .1 CT-Specimens . . . . . . . . . . . . . . . . . . . . . . . . 4

4.1.2 Blunt-Notched Bend Bars . . . . . . . . . . . . . . . 5

4.1.3 Tensile Specimens . . . . . . . . . . . . . . . . . . . 5

4.2 Fractographic Examination . . . . . . . . . . . . . . 6

4.2.1 Blunt-Notched Bend Bars . . . . . . . . . . . . . . . 7

4.2.2 Tensile Specimens . . . . . . . . . . . . . . . . . . 7

4.2.3 Location of Initiation Sites . . . . . . . . . . . . . . 7

4.3 Metallographic Investigations . . . . . . . . . . . . . . 9

5. DISCUSSION . . . . . . . . . . . . . . . 9

5.1 Fracture Stresses in the Various Specimens . . . . . . . . . 9

5.1 .1 CT-Specimens . . . . . . . . . . . . . . . . . . . . . . . . 9

5.1.2 Blunt-Notched Bend Bars . . . . . . . . . . . . . . . . . . 12

5.1.3 Tensile Specimens . . . . . . . . . . . . . . . . . . . . . 12

5.2 Types of Initiation Sites . . . . . . . . . . . . . . . . . . 13

5.3 Scatter of the Fracture Toughness . . . . . . . . . . . . . . 16

5.4 Some Aspects on the Lower Bound Fracture Toughness and the

Transition Temperature . . . . . . . . . . . . . 17

6. CONCLUSIONS . . . . . . . . . . . . . . . . . . . . 20

7. ACKNOWLEDGMENTS . . . . . . . . . . . . . . . . . . . . 20

8. NOMENCLATURE . . . . . . . . . . . . . . . . . . 21

9. REFERENCES . . . . . . . . . . . . . . . 22 

Fracture Behavior of a Pressure Vessel Steel in the Ductile-to-Brittle Transition Region

\author{
Jürgen Heerens* and D.T. Read \\ Fracture and Deformation Division \\ National Institute of Standards and Technology
}

The reasons for the scatter of fracture toughness in the ductileto-brittle transition region, as well as the mechanisms leading to cleavage fracture, have been investigated for a quenched and tempered pressure vessel steel, DIN 20 MnMoNi 55. The fracture surfaces indicate that cleavage fracture starts at one small area in the ligament, the cleavage initiation site. Cleavage initiation occurs ahead of the crack tip at the location of the maximum normal stresses. Fractography and metallography show four different types of initiation sites. The mechanisms which may trigger cleavage fracture at these initiation sites are discussed. The results indiicate that the scatter of fracture toughness is due to the scatter in the distance between the cleavage initiation site and the fatigue crack tip.

Key words: cleavage; fracture stress; inclusions; initiation site; mechanism; origin; scatter; weak link.

\title{
1. INTRODUCTION
}

For characterization of the ductile-to-brittle fracture transition behavior of a steel, the transition curve is normally determined by measuring the fracture toughness as a function of temperature. In connection with the experimental determination of the transition curve, the following facts are generally observed:

- The fracture toughness in the lower transition region exhibits high scatter, which increases with increasing temperature. This scatter band reaches its maximum in the upper transition region. Because of the lar. scatter, many specimens must be tested in order to characterize the fracture toughness of the material in this region.

\footnotetext{
* Permanent Address: GKSS Research Center, Geesthacht, West Germany.
} 
- The transition curve frequently depends on the size and geometry of the specimen as well as on the loading rate used in the fracture test. Consequently, the test results are not directly applicable to a crack in a structure which has a constraint or loading rate different from the test specimen.

Current research on these problems is discussed in [1-3].

The microstructural mechanisms leading to cleavage fracture for quenched and tempered steels are not yet well understood. The literature reports different results regarding the mechanisms of cleavage fracture initiation for this kind of microstructure. The fracture of carbide particles larger than 1 $\mu \mathrm{m}$ seems to trigger cleavage fracture in many mild steels [4]. The carbide particles in quenched and tempered steels are much smaller than $1 \mu \mathrm{m}$ and it is believed that other microstructural parameters, such as the bainite packet size [5] or inclusion clusters [6], are relevant for cleavage fracture. A recent investigation [7] on a tempered MnMoNi steel showed that cleavage fracture proceeds by a micromechanism which involves dislocation interaction.

The present investigation deals with cleavage fracture in a quenched and tempered pressure vessel steel, $20 \mathrm{MnNoNi}$ 55. This steel is similar to type A533B. The objective was to investigate the scatter of fracture toughness in the transition region as well as to examine the micromechanisms which trigger cleavage fracture. The fracture surfaces of CT-specimens, blunt notched bend bars, and tensile specimens were investigated. In each specimen one cleavage initiation site was found. Four different types of initiation sites, which have different fractographic features, were classified. The results show that the scatter of the fracture toughness is caused by the variation of the location of the cleavage initiation sites in the ligament. The fractographic and metallographic results are used to discuss some possible cleavage initiation mechanisms as well as some aspects on both the lower bound toughness and the transition temperature.

\section{MATERIAL}

The material used in this study was DIN 20 MnMoNi 55 steel from a forged boiler bottom segment. The chemical composition of this steel is similar to 
ASTM A533B; see table 1. The heat treatment of the material is shown in figure 1. The size of the heat-treated block was about $600 \times 300 \times 300 \mathrm{~mm}$. All specimens were machined from three adjacent $25 \mathrm{~mm}$ thick slices taken from one heat treated block. The orientation of the fracture surfaces was the same for all types of specimens. The microstructure of the heat treated material is shown in figure $2 a$. The average ferrite grain size of the alloy is about $30 \mu \mathrm{m}$. Rod-like carbide particles which are arranged in parallel rows can be observed in the individual ferrite grains. The size of the carbide particles is about 0.2 to $0.5 \mu \mathrm{m}$. Large isolated inclusions as well as clusters of these inclusions can be observed on polished surfaces. A typical example of these inclusion clusters is shown in figure $2 \mathrm{~b}$.

Table 1. Composition of $20 \mathrm{MnNoNi55} \mathrm{(}$ A533B) in mass percent

$\begin{array}{ccccccc}\text { C } & \text { Si } & \text { Mn } & \text { P } & \text { S } & \text { Cr } & \text { V } \\ 0.19 & 0.2 & 1.29 & 0.007 & 0.008 & 0.12 & 0.02 \\ & & & & & & \\ \text { Cu } & \text { Al } & \text { Ni } & \text { Mo } & \text { Sn } & \text { Co } & \text { As } \\ 0.11 & 0.015 & 0.80 & 0.53 & 0.012 & 0.014 & 0.030\end{array}$

$\begin{array}{ccc}\mathrm{Sb} & \mathrm{Ti} & \mathrm{Fe} \\ 0.030 & 0.050 & \mathrm{bal}\end{array}$


The specimens used in this study are shown in figure 3. For the determination of the fracture toughness, precracked CT-specimens were used. All specimens were fatigue precracked at room temperature with a load ratio of $\mathrm{P}_{\min } / \mathrm{P}_{\max }=0.1$. The $\mathrm{K}_{\max }$-value for the final 1 to $2 \mathrm{~mm}$ of precracking was about 500 to $600 \mathrm{~N} / \mathrm{mm}^{3} / 2$. All specimens were side grooved 20 percent after precracking. The J-integral was calculated according to ASTM E 813-81 [8] by using the analysis for the multiple specimen technique. The blunt-notched bend bars were machined and tested under 4 point bending as shown in [9]. The crosshead displacement rate was $0.5 \mathrm{~mm} / \mathrm{min}$ for the CT-specimen and bend bars. The tensile specimens were tested with a displacement rate of $1 \mathrm{~mm} / \mathrm{min}$. For cooling the specimens, a bath of ethanol cooled with liquid nitrogen or a bath of pure liquid nitrogen was used, depending on the test temperature. In either case the temperature of the specimen was monitored by a thermocouple attached to the surface of the specimen or located within a small hole in the specimen. For the metallographic examinations, the surfaces were electropolished using a mixture of $25 \mathrm{~g} \mathrm{CrO}_{3}$ in $133 \mathrm{ml}$ acetic acid. Etching was done with 2 to 3 percent nital. For qualitative analysis of the inclusions, an energy dispersive analyzer combined with a scanning electron microscope (SEM) was used.

\section{RESULTS}

\subsection{Fracture Behavior of the Various Specimens}

\subsubsection{CT-Specimens}

The critical J-values, $J_{C}$, for cleavage fracture of $30 \mathrm{CT}$ specimens, were measured in a temperature range of -90 to $-45{ }^{\circ} \mathrm{C}$. In order to determine the scatterband of $J_{C}$ in this temperature range, a number of specimens were tested at -90 and $-60{ }^{\circ} \mathrm{C}$, respectively. The resulting data, figure 4 , show that the scatter in $J_{C}$ increases significantly with increasing temperature. For temperatures higher than $-60{ }^{\circ} \mathrm{C}$ the scatterband seems to increase further.

Within the range of -60 to $-90{ }^{\circ} \mathrm{C}$, the $\mathrm{J}$-level for initiation of ductile tearing, $J_{i}$, was found to be in the range of 100 to $150 \mathrm{~N} / \mathrm{mm}$. At this $J_{i}$ level, local dimpled rupture can be observed at the crack front. This $J_{i}$. 
level was determined by fractography using an SEM. The Jic-value of the material at room temperature is about 200 to $300 \mathrm{~N} / \mathrm{mm}$ as shom in a previous study [10]. The toughness values in figure 4 represent the fracture toughness of the steel in the upper transition region, that is, the region in which cleavage fracture with or without ductile tearing can occur.

\subsubsection{Blunt-Notched Bend Bars}

In order to apply the finite element solutions of [9] to the present work, cleavage fracture of the specimens must occur uncer small scale yielding conditions. For this reason all bend bar tests were conducted at the relatively low temperature of $-196{ }^{\circ} \mathrm{C}$, where all specimens failed by cleavage fracture under small scale yielding conditions.

\subsubsection{Tensile Specimens}

The lower yield strength, $\sigma_{0.2}$, and the ultimate tensile strength, $\sigma_{u}$, were measured as functions of temperature (fig.5). The flow properties at various temperatures are listed in table 2.

Table 2. Flow property of the specimen material at the various test temperatures

\begin{tabular}{cccc}
\hline & & & \\
${ }^{\circ} \mathrm{C}$ & $\sigma_{0} 2^{2}$ & $\mathrm{~N} / \mathrm{mm}^{2}$ & \\
\hline-90 & 550 & 210000 & 0.09 \\
-85 & 545 & 210000 & 0.09 \\
-70 & 520 & 210000 & 0.095 \\
-60 & 500 & 210000 & 0.1 \\
-55 & 495 & 210000 & 0.1 \\
\hline
\end{tabular}


At temperatures below $-178{ }^{\circ} \mathrm{C}$ all tensile specimens failed by cleavage fracture; at higher temperatures they failed by ductile tearing.

At $-196{ }^{\circ} \mathrm{C}$ cleavage fracture of the specimens occurred before the specimen started necking, whereas at $-178{ }^{\circ} \mathrm{C}$ cleavage fracture occurred in the necked area of the specimen, but not at the minimum cross section.

\subsection{Fractographic Examination}

The fracture surfaces of the specimens were carefully investigated. The objective was to find evidence for the microstructural mechanisms leading to cleavage fracture.

At low magnification, the fracture surfaces of each type of specimen exhibited macroscopic river patterns which originated at one small area on the fracture surface. As shown in figure 6 , these river patterns seem to be produced by the intersection of macroscopic fracture planes with different orientations. Fractographic examinations of the center of the macroscopic river patterns at high magnifications using an SEM revealed fine river patterns. In all specimens these river patterns could be traced to a single area including one cleavage facet, or, sometimes, a few. These areas are referred to as initiation sites. Four types of initiation sites were found in the SEM examination of 26 CT specimens.

The cleavage facets at the initiation site had sizes ranging from 55 to $87 \mu \mathrm{m}$. In some cases an inclusion was found in the cleavage facet of the initiation site. An example is shown in figure 7. In cases in which a facet with an inclusion was found at the initiation site, both fracture surfaces of the specimen were investigated in order to find out whether this inclusion was fractured. In all cases debonding between the inclusion and the matrix was observed, and the inclusions were apparently not fractured, see figure 8 . The sizes of the inclusions ranged from 2 to $8 \mu \mathrm{m}$.

In two of the $26 \mathrm{CT}$ specimens, a cluster of large inclusions was found at the initiation site. These inclusion clusters were similar to those found in the tensile specimen discussed in Section 4.2.2.

The energy dispersive analysis of the various inclusions show mainly the elements Mn and S, and traces of Mn, S, and traces of Si, Ti, and Cu.

For $\mathrm{J}_{\mathrm{C}}$-values higher than $\mathrm{J}_{i}$, the specimens had ductile tearing along the 
crack front followed by cleavage. In figure 9, the average extension, $\Delta a$, of ductile tearing at the crack front is shown to increase with increasing $\mathrm{J}_{\mathrm{C}}$. Furthermore, within the temperature range investigated, all specimens fall on one J-R curve.

For higher $\mathrm{J}_{\mathrm{C}}$-values $\left(\mathrm{J}_{\mathrm{C}}>\mathrm{J}_{\mathrm{IC}}\right.$ ), the initiation site was frequently found close to a local zone of ductile tearing, $\Delta a_{L}$. This zone was always significantly larger than the average of ductile tearing, $\Delta a$, along the crack front; see figure 10. The fractographic results for the CT-specimens are summarized in table 3 .

\subsubsection{Blunt-Notched Bend Bars}

The fracture surfaces of all four bend bars showed cleavage fracture. Also in these specimens one initiation site could be found in each specimen. In all specimens a single cleavage facet was found at the initiation site. No inclusions were found on the facets. The initiation site was always located at a certain distance ahead of the notch tip.

\subsubsection{Tensile specimens}

All tensile specimens that failed by cleavage fracture showed macroscopic river patterns like those in the other two types of specimens; see figure 11 . In all three specimens a cluster of large inclusions was found at the initiation site. These clusters are similar to the clusters found in two of the 26 CT specimens. An example of the morphology of these clusters is shown in figure 11b. Debonding between the inclusions and the matrix was observed in all cases. At the border of the inclusion cluster a number of separate cleavage facets, which seemed to be the initiation site, were found.

\subsubsection{Location of Initiation Sites}

The center of the river pattern was assumed to be the cleavage initiation site of a specimen. For all CT-specimens and blunt notched bend bars the location of the initiation site was determined. The distance between the initiation site and the fatigue crack tip was measured; this distance was called $r_{c}$. In addition the distance between the centerline of the specimen and the initiation site was measured; this distance was called $z$. The results of these measurements are shown in figure 12 . 
Table 3. Fractographic results for the CT-specimens

\begin{tabular}{|c|c|c|c|c|c|c|}
\hline $\begin{array}{c}\text { Specimen } \\
\#\end{array}$ & $\begin{array}{c}\mathrm{J}_{\mathrm{C}} \\
{[\mathrm{N} / \mathrm{mm}]}\end{array}$ & $\begin{array}{c}\mathrm{T} \\
{\left[{ }^{\circ} \mathrm{C}\right]}\end{array}$ & $\begin{array}{c}\text { Initiation } \\
\text { Site }\end{array}$ & $\begin{array}{c}\mathrm{r}_{\mathrm{c}} \\
{[\mathrm{mm}]}\end{array}$ & $\begin{array}{c}\mathrm{z} \\
{[\mathrm{mm}]}\end{array}$ & $\begin{array}{l}\Delta \mathrm{a}_{\mathrm{L}} \\
{[\mathrm{mm}]}\end{array}$ \\
\hline $\mathrm{EP} 7$ & 184 & -90 & Facet & 0.415 & 1.0 & - \\
\hline EP 10 & 180 & -90 & Facet & 0.271 & 2.5 & - \\
\hline EP 1 & 170 & -90 & Facet & 0.310 & 2.2 & - \\
\hline EP 6 & 157 & -90 & Facet & 0.290 & 5.0 & - \\
\hline EL 11 & 124 & -90 & Facet & 0.900 & 4.5 & - \\
\hline EL 12 & 180 & -85 & Inclusion & 0.780 & 0.3 & - \\
\hline EL 4 & 100 & -70 & Facet & 0.170 & 2.2 & - \\
\hline EL 6 & 150 & -70 & Inclusion & 0.350 & 3.0 & - \\
\hline EL 3 & 500 & -70 & Inclusion & 1.700 & 2.3 & - \\
\hline EP 12 & 60 & -60 & Inclusion & 0.250 & 0.0 & - \\
\hline EP 8 & 120 & -60 & Cluster & 1.500 & 6.5 & - \\
\hline EQ 3 & 124 & -60 & Facet & 0.223 & 3.0 & - \\
\hline $\mathrm{EP} 4$ & 168 & -60 & Facet & 0.490 & 0.5 & - \\
\hline EL 7 & 195 & -60 & Inclusion & 0.750 & 2.1 & - \\
\hline EP 9 & 215 & -60 & Inclusion & 1.035 & 2.0 & - \\
\hline EQ 4 & 286 & -60 & Facet & 0.750 & 2.5 & - \\
\hline EP 2 & 304 & -60 & Facet & 0.980 & 1.5 & - \\
\hline ⿷Q 2 & 340 & -60 & Local Tearing & 0.800 & 3.0 & 0.70 \\
\hline EP 14 & 434 & -60 & Local Tearing & 1.030 & 1.2 & 1.00 \\
\hline EP 15 & 448 & -60 & Local Tearing & 1.780 & 1.0 & 2.01 \\
\hline EP 3 & 513 & -60 & Local Tearing & 1.250 & 0.5 & 1.25 \\
\hline EQ 1 & 560 & -60 & Local Tearing & 1.800 & 1.5 & 1.40 \\
\hline EP 16 & 630 & -60 & Facet & 1.500 & 1.1 & - \\
\hline EL 11 & 190 & -55 & Facet & 0.328 & 5.0 & - \\
\hline EL 10 & 250 & -55 & Cluster & 2.320 & 1.7 & - \\
\hline EL 5 & 445 & -55 & Facet & 1.320 & 3.4 & - \\
\hline
\end{tabular}




\subsection{Metallographic Investigations}

To find additional evidence for the cleavage crack nucleation mechanisms, some CT and tensile specimens were sectioned perpendicular to the fracture surface. The cross sections were then electropolished and etched. By this technique, a number of isolated cleavage microcracks were found in the area close $(-200 \mu \mathrm{m})$ to the fracture surface. Most of these cracks were deflected or arrested at grain boundaries, see figure 13. Figure 14 shows the behavior of the carbide particles at high strains $(\simeq 10$ percent) in a tensile specimen tested at $-196{ }^{\circ} \mathrm{C}$. Some of the carbide particles have fractured but most seem only to generate voids. Cleavage microcracks associated with broken carbide particles were not found.

\section{DISCUSSION}

\subsection{Fracture Stresses in the Various Specimens}

Many investigations on cleavage fracture [1-7] have shown that the normal stresses in a material seem to have a close correlation to the cleavage fracture behavior of a material. The fact that the cleavage initiation sites can be localized in all types of specimens used in the present study provides the opportunity to investigate this correlation in detail. For this purpose, the normal stress at the initiation site at the moment of cleavage fracture was calculated for all specimens by using the approaches described below. The normal stress at the initiation site at the moment of cleavage fracture was considered to be the fracture stress $\sigma_{f}$ of the specimen.

\subsubsection{CT-Specimens}

A number of solutions are available for the calculation of the normal stresses ahead of a stationary crack [11-15]. The solutions are based on different assumptions for shape of the crack tip or the flow property of the material.

It has been shown $[12,13]$ that for a blunted crack the normal stresses have a maximum at a certain distance ahead of the crack tip, sce figure 15. In figure 15, the actual distance from the crack tip was normalized. Therefore, the value A indicates the normalized distance. For a sharp crack the normal stresses at the tip become infinite when the specimen is loaded. 
For the calculation of the fracture stresses of the CT specimens, Schwalbe's [14] solution for normal stresses was used. This solution describes the stresses at a sharp crack, and, therefore, it does not show a stress maximum ahead of the tip. To account for the fact that cleavage fracture of a specimen always occurred after crack blunting, the maximum of the normal stresses was considered to be at the normalized distance $A_{m}=$ $2.7 \cdot 10^{-3}$ in front of the tip as shown in the finite element calculations of [12]. The solution given in [14] was used only for distances $A>A_{m}$. For distances $A \leq A_{m}$, that is, the region between the crack tip and the normal stress maximum, the normal stresses were assumed to have the same value as at the normalized distance $A_{m}$. Figure 15 shows a comparison between this approach and the solutions taken from [11-13]. This approach leads to an overestimation of the normal stresses in the range $A<A_{m}$, but it gives a good estimation of the normal stresses at the distances $A>A_{m}$ and for the maximum itself. It will be seen in the next section that this overestimation in the stress calculation for the range $A<A_{m}$ is not essential for the results of this paper.

Using these approaches, the fracture stresses of the CT-specimens, $\sigma_{f}$, were estimated as following:

For $A>A_{m}$, that is the region ahead of the normal stress maximum:

$$
\sigma_{\mathrm{f}}=\left[\frac{0.3}{\mathrm{~A}+0.1}\left(\frac{0.04}{\mathrm{~A}}\right)^{\mathrm{n} / \mathrm{n}+1}\right] \cdot \sigma_{0.2} .
$$

where $\mathrm{n}$ is the strain hardening exponent.

For $A \leq A_{m}$, that is the region between crack tip and normal stress maximum:

$$
\left.\sigma_{\mathrm{f}}=\sigma_{\mathrm{y}}^{\max }=\frac{0.3}{\mathrm{~A}_{\mathrm{m}}+0.1}\left(\frac{0.04}{\mathrm{~A}_{\mathrm{m}}}\right) \mathrm{n} / \mathrm{n}+1\right] \cdot \sigma_{0.2}
$$

The normalized distance $A$ is defined as

$$
A=\frac{r_{c}-\delta_{c} / 2}{\left(K_{c} / \sigma_{0} \cdot 2\right)^{2}}
$$


$\mathrm{J}_{\mathrm{C}}$ was converted to $\mathrm{K}_{\mathrm{C}}$ by

$$
\mathrm{K}_{\mathrm{C}}=\left(\frac{\mathrm{J}_{\mathrm{C}} \cdot \mathrm{E}}{\left(1-\nu^{2}\right)}\right)^{0.5}
$$

The crack tip opening displacement $\delta_{c}$ was used as defined in reference [16] by

$$
\delta_{\mathrm{c}}=\mathrm{d}_{\mathrm{n}} \mathrm{J}_{\mathrm{c}} / \sigma_{0}
$$

For an estimation of both the strain hardening exponent $\mathrm{n}$ and the flow strength $\sigma_{0}$, the procedure proposed in [17] was used. In this procedure the true stress-strain curve of a uniaxial tensile test is approximated by a power law. All data regarding the material flow property used for the calculation of the fracture stresses are shown in table 2 .

The calculations of the fracture stress $\sigma_{f}$ are based on the assumptions of plane strain, small scale yielding and no crack growth. These requirements are not satisfied for most of the tested specimens. Finite element calculations [18] show that for side grooved specimens the center of the specimen deforms under conditions close to plane strain up to load values above the limit load. Reference [19] showed that the normal stress distribution in front of the crack tip of a bend specimen can be well estimated by the small scale yielding solution up to J-levels of about $\left(\mathrm{W}-\mathrm{a}_{0}\right) \sigma_{0.2} / 30$. This corresponds to a J-level of about $400 \mathrm{~N} / \mathrm{mm}$ for the CT specimen tested here at $-60^{\circ} \mathrm{C}$. For this $\mathrm{J}$-level the average length of ductile tearing at the crack front $\Delta$ a remains smaller than half the distance between the fatigue crack tip and the location of the maximum of the normal stresses in front of the crack tip. These considerations show that for those tests with $\mathrm{J}_{\mathrm{C}}$ of less than $400 \mathrm{~N} / \mathrm{mm}$, the assumptions used to calculate of are valid and the values of $\sigma_{f}$ are accurate.

For $J_{c}$ values higher than $400 \mathrm{~N} / \mathrm{mm}$ the calculated fracture stresses arc more uncertain. For specimens which showed cleavage initiation at a local zone of ductile tearing, the assumption of an approximately stationary crack is not satisfied and the fracture stress was not calculated. 


\subsubsection{Blunt-Notched Bend Bars}

For the notched bend bars the fracture stresses were calculated using the small scale yielding finite element solution given in [9]. A comparison between the fractographic results and the normal stress distribution at the notch shows that the initiation site is not always located at the normal stress maximum. Thus, a slightly different procedure than that proposed in [9] was used to calculate the fracture stresses. At first the stress distribution at cleavage initiation was determined by an interpolation between the loading steps given by the finite element solutions. The fracture stress was then estimated by determining the normal stress at the location of the initiation site in front of the tip. This procedure assures that the fracture stress represents the actual normal stress at the initiation site, whereas the procedure proposed in [9] would lead to a slight overestimation of the fracture stress.

\subsubsection{Tensile Specimens}

For the tensile specimens, $\sigma_{f}$ was calculated by

$$
\sigma_{\mathrm{f}}=\mathrm{F}_{\mathrm{c}} / \mathrm{S}
$$

where $F_{C}$ is the failure load of the specimen and $S$ indicates the area of the cleavage fracture surface.

All fracture stresses for the various specimens are shown in figure 16; different types of specimens seem to give essentially the same fracture stress for a particular kind of initiation site. For a single cleavage facet at the initiation site, the fracture stresses seem to be the same for both CT specimens and bend bars.

These two specimen types were tested at different temperatures. The strains at the initiation site at the moment of cleavage fracture are expected to be quite different. Therefore, the fracture stress seems to be independent of the temperature as well as independent of the strain at the cleavage initiation site.

Figure 16 also indicates that the fracture stresses for an inclusion cluster are nearly the same for both the tensile and the CT specimens. The results show that clusters of inclusions can cause a significantly lower 
fracture stress than a single cleavage facet at the initiation site. More experimental results are needed before final conclusions can be drawn about the influence of inclusion clusters on cleavage fracture.

\subsection{Types of Initiation Sites}

The calculations of $\sigma_{f}$ are based on isotropic homogeneous deformation behavior. This assumption is not satisfied for the small volume in which initiation of cleavage seems to occur. Therefore, the fracture stresses have to be seen as an average of the normal stresses in the volume surrounding the initiation site. Despite this restriction, the fracture stresses may be used for a discussion of some possible micromechanisms which may occur in the few grains at the initiation site and which may lead to cleavage fracture. Considering the fractographic results, four different types of initiation sites having different fractographic features can be classified.

Type A: Cleavage Facet at the Initiation Site.

This type was found mainly for $\mathrm{J}_{\mathrm{C}}$-values smaller than $\mathrm{J}_{\mathrm{Ic}_{\mathrm{c}}}$ as well as in all bend bars. This type appears mainlyk at low temperatures because in all the CT specimens as well as in all bend bars tested at -90 and at $-196{ }^{\circ} \mathrm{C}$ this type was found. The fracture stress was always higher than $1700 \mathrm{~N} / \mathrm{mm}^{2}$ for this type of initiation site. A possible, micromechanism which could explain the fractographic observations, as well as the level of fracture stress, will now be discussed. It may be assumed that cleavage fracture at an initiation site takes place in a three-step process as follows:

1. Nucleation of a Cleavage Microcrack. Since the river pattern can be traced back to an area smaller than the cleavage facet size and smaller than the grain size, cleavage crack nucleation is a very localized event which occurs within a grain or at a grain boundary. The metallographic results show that small carbides can fracture and therefore can produce a microcrack when the material is deformed, see figure 14. The critical stress necessary to drive a carbidesized cleavage microcrack into the adjacent ferrite matrix may be estimated by 


$$
\sigma_{c}=\frac{\sqrt{4 \mathrm{E \gamma}}}{\left(1-\nu^{2}\right)} \mathrm{d}^{-0.5}
$$

as proposed by Orowan [20]. Using the effective fracture surface energy $\gamma=14 \mathrm{~J} / \mathrm{m}^{2}$, which is reasonable for a cleavage microcrack which encounters the ferrite-carbide interface [21], and using a microcrack size of $\mathrm{d}=0.5 \mu \mathrm{m}$, which is approximately the size of the biggest carbides, the critical stress, $\sigma_{\mathrm{C}}$, is about $5000 \mathrm{~N} / \mathrm{mm}^{2}$. This stress value is much higher than the calculated fracture stresses for any initiation site in this material. Therefore it seems unlikely that fracture of the single carbide determines the fracture of the specimen. This conclusion is also in agreement with the fractographic results, which show no evidence that a fractured particle is $i$ l.ved in the cleavage microcrack nucleation. These findings suppc the assumption that mechanisms other than particlefracture cause cleavage microcrack nucleation and cleavage fracture of a specimen.

2. Cleavage Microcrack Extension. Once the cleavage microcrack has nucleated by a mechanism other than particle fracture, the microcrack may grow within one grain or across a few adjacent grains which have a low mismatch in crystallographic orientation. The stress necessary to drive a cleavage microcrack is very low for this situation, because the effective fracture surface energy $\gamma$ for a cleavage crack in a ferrite single crystal is as low as $2 \mathrm{~J} / \mathrm{m}^{2}[3$, 22]. At this stage, the cleavage microcrack may form a cleavage facet which can be observed at the initiation site by fractographic examination.

3. Cleavage Microcrack at a Grain Boundary. The fact that grain-sized cleavage microcracks can be found in the material (fig. 13) indicates that a grain boundary can be an obstacle for a cleavage microcrack. It can be expected that the resistance of a grain boundary increases with increasing crystallographic mismatch. This mismatch may promote an arrest or deflection of the cleavage crack, as shown in figure 13. Fractography shows that the borders of the 
cleavage facets are formed by a deflection of the spreading cleavage crack. Therefore, the borders of the cleavage facets might be grain boundaries between grains which have a relatively high mismatch in crystallographic orientation. For an estimation of the critical stress necessary to drive a cleavage crack across such a grain boundary, eq (7) may be used. The critical surface energy $\gamma$ for a cleavage microcrack encountering this kind of grain boundary may be assumed to be within the range of 100 to $190 \mathrm{~J} / \mathrm{m}^{2}$ as proposed in [3, 23]. Thus, the critical stress for a cleavage microcrack which has the size of the cleavage facet $(60 \mu \mathrm{m})$ is in the range of 1250 to $1700 \mathrm{~N} / \mathrm{mm}^{2}$. This is in agreement with the fracture stresses calculated from the present experiments; see figure 16. Therefore it is possible that the critical step for cleavage fracture is the ability of a cleavage microcrack to cross the first high-mismatch grain boundaries which surround the nucleation site.

As a consequence of these cleavage initiation mechanisms, it can be assumed that cleavage crack nucleation is necessary but not sufficient for cleavage fracture. Only for situations in which nucleation occurs at a stress level high enough to drive the crack across the grain boundaries does fracture of the specimen occur. Below a certain stress level, all nucleated cleavage cracks become arrested at the grain boundaries. This may be the reason why all fracture stresses associated with type A initiation site are higher than $1700 \mathrm{~N} / \mathrm{mm}^{2}$. The size of the cleavage facets is approximately two times larger than the average ferrite grain size. The reason for this has not been closely investigated yet. Possibly the prior austenite grain size is related to the facet size.

Type B: Inclusion at the Cleavage Facet is the Initiation Site.

Figure 16 indicates that the appearance of an inclusion on the cleavageinitiation site occurs mainly at higher temperatures because no bend bars or CT specimens tested at -196 or $-90{ }^{\circ} \mathrm{C}$ showed this type of initiation. In addition it seems that the appearance of an inclusion is associated with a slightly lower fracture stress. 
Type C: Cleavage Initiation at a Cluster of Inclusions.

This type was found in all tensile specimens but only in 2 of $26 \mathrm{CT}$ specimens. The fracture stresses for this type of initiation are significantly lower than the fracture stresses for Types A and B; possibly the cluster of inclusions causes a stress elevation in the surrounding volume and therefore promotes cleavage fracture. The cleavage initiation mechanism itself seems to be similar to Type A, because also in this case single cleavage facets at the initiation sites are located close to the cluster, see figure $9 \mathrm{~b}$. The fact that this type of initiation site was found mainly in the tensile specimen can be explained by the large active volume of this specimen. This large active volume leads to a high probability of occurrence of such a cluster, whereas for a CT specimen, which has a small active volume, this probability is very low.

Type D: Cleavage Initiation at Local Zone of Ductile Tearing.

This type becomes dominant at $\mathrm{J}_{\mathrm{C}}$-values higher than $\mathrm{J}_{\mathrm{Ic}}$. As shown in Section 5.4 the length of the local zone of ductile tearing, $\Delta a_{L}$, is always equal to the distance between the original fatigue crack tip and the normal stress peak in front of the crack tip at the moment of cleavage fracture. Therefore, it seems that the tearing crack grows locally ahead of the main crack front and triggers cleavage fracture at the location of maximum normal stress corresponding to the original stationary fatigue pre-crack.

\subsection{Scatter of the Fracture Toughness}

Figures $17 \mathrm{a}$ and $\mathrm{b}$ plot the $\mathrm{J}_{\mathrm{c}}$-values versus the $\mathrm{r}_{\mathrm{c}}$-values for the $\mathrm{CT}$ specimen tested at -90 and $-60{ }^{\circ} \mathrm{C}$ respectively. Two lines indicate the range in which the normal stresses in front of the crack tip are higher than 958 of $\sigma_{\mathrm{y}}^{\max }$. This range is approximately determined by $2 \cdot 10^{-3}<\mathrm{A}_{\mathrm{m}}<3.5 \cdot 10^{-3}$, see figure 15 .

Most of the $r_{c}-J_{C}$ data points fall into this range; only a few are located slightly in front of the normal stress maximum. This result shows that the $\mathrm{J}_{\mathrm{C}}$-values are essentially controlled by $\mathrm{r}_{\mathrm{C}}$, the distance between the fatigue crack tip and the cleavage initiation site. This distance, $r_{c}$, characterizes how far the normal stress peak must move into the ligament in order to find the cleavage initiation site. Comparing the $\mathrm{r}_{\mathrm{c}}$-values for 
$-60{ }^{\circ} \mathrm{C}$ with those $-90{ }^{\circ} \mathrm{C}$, it can be seen that the scatter of $\mathrm{r}_{\mathrm{c}}$ decreases significantly with decreasing temperature, and so does the scatter of $\mathrm{J}_{\mathrm{C}}$. This shows that the scatter of the toughness values, $\mathrm{J}_{C}$, is caused mainly by the scatter of the location of the cleavage initiation sites in the ligament.

The reduction of the scatter of the $r_{c}$-values with lower temperature indicates that the density of the cleavage initiation sites at the crack tip increases with lower temperature, possibly because of the increase of the normal stresses due to the temperature dependence of the yield strength. These higher normal stresses at the crack tip may give more cleavage cracks the ability to spread out than at higher temperatures. The change in temperature from -60 to $-90{ }^{\circ} \mathrm{C}$ causes an increase of the normal stresses of about 10 percent. This change is relatively small. It is hard to believe that this small stress elevation is the only reason for the large change in fracture behavior. Possibly the temperature influences more than just the stress elevation. However, the small variation of normal stresses is the only clear reason for the variation of the density of the initiation sites, and as a result, the variation in fracture behavior of the CT specimen. If this were so, then any kind of small variations in yield strength would lead to large changes in brittle fracture behavior.

\subsection{Some Aspects on the Lower Bound Fracture Toughness and the Transition Temperature}

The approach discussed in Section 5.3 does not explain the existence of a lower bound fracture toughness because, in principle, a cleavage initiation site may be located very close to the crack tip. Considering the correlation of $J_{c}$ with $r_{c}$, this situation would lead to a vanishing $J_{c}$ value as $r_{c}$ approaches zero.

In all the tests conducted in this study, no $r_{C}$ values smaller than 170 $\mu \mathrm{m}$ have been found. This indicates that the initiation of cleavage close to the crack tip is very unlikely.

An interpretation of this result can be made by the RKR-Model [24] which postulates that cleavage can only occur if the fracture stress is reached or exceeded over a critical distance, called $\mathrm{X}$. According to the normal stress behavior at the crack tip, this requirement can only be satisfied when $J$ is 
high enough to provide a normal stress peak sufficiently wide enough to cover the initiation site.

The lower bound toughness would then be characterized by a situation in which the critical length, $X$, which covers an initiation site, equals the width of the normal stress peak at the stress level necessary to initiate cleavage fracture.

Results of RKR calculations are shown in figure 4 for critical distances $X=100$ and $200 \mu \mathrm{m}$ using the fracture stress found for the CT specimens for the type A initiation site. It is not clear yet whether this model predicts the lower bound toughness of the specimen because there are not enough experimental data for small $\mathrm{r}_{\mathrm{c}}$ values. Recent results [25] indicate that the minimum of the $r_{c}$ values, that is $r_{c m i n}$, decreases with decreasing temperature; see figure 18. This is in agreement with the approach described above because with decreasing temperature the width of the normal stress peak at a given stress level increases due to the increase of the yield strength. Therefore, the requirement of reaching or exceeding the fracture stress over the critical distance $X$ can be satisfied at lower $J$ levels for which the normal stress peak is close to the crack tip.

Cleavage fracture will occur at an initiation site if the normal stress exceeds a certain stress level, called the activation stress. Scatter results because cleavage occurs when the normal stress peak exceeds the lowest activation stress of all initiation sites ahead of the crack tip. If the activation stress were never exceeded, the specimen would fail by ductile fracture. The normal stress peak is a function of the yield strength and work hardening of the steel at the temperature and constraint level existing at the initiation site.

For a discussion of the activation stress, the fracture stresses of the CT specimens may be used. Figure 16 shows that the majority of the type-A initiation sites have a fracture stress higher than $\sigma_{\mathrm{A}}=1720 \mathrm{~N} / \mathrm{mm}^{2}$; only 2 of 26 specimens had a lower fracture stress. A lower fracture stress $\sigma_{\mathrm{C}}$ of 1500 $\mathrm{N} / \mathrm{mm}^{2}$ was found to be associated with initiation sites of type $C$. The fact that only 2 of 26 specimens exhibited type $C$ initiation sites indicates that the density of this type of initiation site is low compared to the density of initiation sites which become activated at stress levels higher than $\sigma_{A}$. For a situation in which the normal stress peak has a stress level lower then $\sigma_{\mathrm{A}}$ 
but higher than $\sigma_{C}$, it can be expected that only the type $C$ initiation sites could be activated. Due to the low density of type C initiation sites, the $r_{C}$-values for this situation will show a large scatter, and therefore $J_{C}$ will show a large scatter. For a situation in which the normal stress peak becomes lower then $\sigma_{C}$, cleavage fracture of a specimen becomes impossible.

If the normal stress peak in the CT-specimen can be estimated by eq (2), then the temperatures at which the stress peak has a level of $\sigma_{\mathrm{B}}$ and $\sigma_{\mathrm{C}}$ respectively can be calculated using the temperature versus yield strength relationship shown in figure 5:

$$
\begin{aligned}
& \sigma_{\mathrm{A}}=\left.\sigma_{0.2}\right|_{\mathrm{T}_{\mathrm{A}}} 2.921(14.81)^{\mathrm{n} /(\mathrm{n}+1)} \\
& { }_{\sigma_{\mathrm{C}}}=\left.\sigma_{0.2}\right|_{\mathrm{T}_{\mathrm{C}}} 2.921(14.81)^{\mathrm{n} /(\mathrm{n}+1)}
\end{aligned}
$$

This estimation gives temperatures of $\mathrm{T}_{\mathrm{A}}=-30{ }^{\circ} \mathrm{C}$ and $\mathrm{T}_{\mathrm{C}}>$ room temperature. At the present stage of this study it is not possible to evaluate this approach because no data are available yet for this temperature range. But figure 4 seems to indicate that the scatter of $J_{C}$ becomes very large for $\mathrm{T}>-30{ }^{\circ} \mathrm{C}$ as predicted by this estimate.

At the present state of this study there are no experimental data available for specimens thicker than $B=20 \mathrm{~mm}$, but the present data suggest a few points concerning thickness effects and the transition behavior which may be checked in a further study.

With increasing thickness, the number of cleavage initiation sites within a certain distance from the crack tip will increase because of the increasing length of the crack front. This can lead to a reduction of the $r_{C}$-values and therefore to a reduction in the scatter of the $\mathrm{J}_{C}$-values, as observed in many experimental studies. 
Figure 19 indicates that cleavage initiation occurs mainly in the center region of the specimen. The effective thickness area in which cleavage can

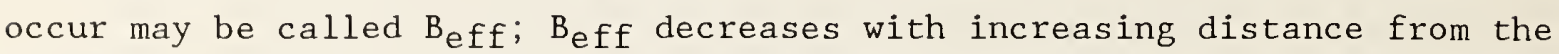
crack tip. The initiation sites located far from the crack tip are related to higher $J_{C}$-values than at initiation sites located close to the tip ( $s e e r_{C}-J_{C}$ relationship in figure 17 ). Finite element solutions show that with increasing $\mathrm{J}$ the loss of triaxiality of the stresses grows gradually from the side surface of the specimen into the specimen. This loss of triaxiality leads to lower normal stresses. Therefore, the location of the cleavage initiation sites tends to be located nearer to the center of the specimen with increasing distance from the crack tip. The J-value at which Beff approaches zero seems to characterize the situation at which the normal stress peak becomes lower than $\sigma_{\mathrm{A}}$ due to the loss of triaxiality of the stresses.

\section{CONCLUSIONS}

One cleavage initiation site was found on the fracture surface of each specimen, including fatigue cracked CT-specimens, blunt notched bend bars, and tensile specimens.

Four different types of cleavage initiation sites were classified:

Type A: Cleavage facet at the initiation site

Type B: Nonfractured inclusion at the initiation site

Type C: Cluster of inclusions at the initiation site

Type D: Initiation at a local zone of ductile tearing

In the CT-specimens, cleavage crack initiation occurs at the location of the maximum normal stresses ahead of the crack tip. The scatter of fracture toughness in the upper transition region is due to the scatter of the distance between the fatigue crack tip and the cleavage initiation site.

\section{ACKNOWLEDGMENTS}

The first author would like to thank the GKSS-Forschungszentrum, Geesthacht, West Germany and the National Institute of Standards and Technology, Boulder, for supporting his sabbatical at NIST. The authors 
gratefully acknowledge many helpful discussions with H.I. McHenry. We would also like to thank P.T. Purtscher and Y.-W. Cheng for their contributions and J.D. McColskey for technical support.

\section{NOMENCLATURE}

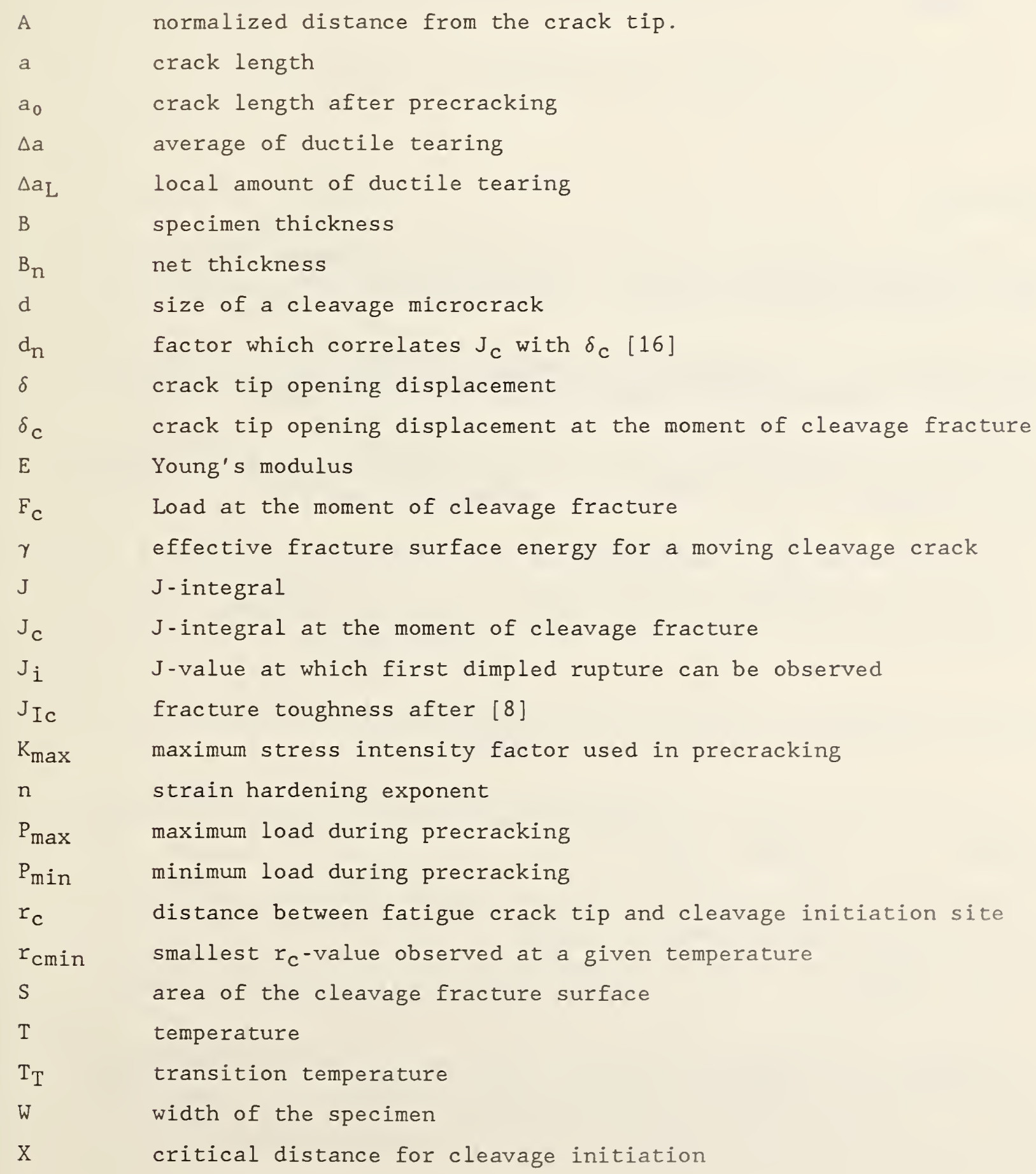




$\begin{array}{ll}\sigma_{0.2} & \text { lower yield strength } \\ \sigma_{\mathrm{u}} & \text { ultimate tensile strength } \\ \sigma_{\mathrm{A}} & \text { lowest fracture stress for initiation Type A of the CT-specimen } \\ \sigma_{\mathrm{C}} & \text { lowest fracture stress for initiation Type } \mathrm{C} \text { of the CT-specimen } \\ \sigma_{\mathrm{M}} & \text { lowest fracture stress of all initiation sites at the crack tip } \\ \sigma_{\mathrm{CT}}^{\max } & \text { stress level of the normal stress peak at the crack tip in a CT- } \\ \sigma_{\mathrm{max}}^{\max } & \text { an estimation of } \sigma_{\mathrm{CT}} \text { by using equation } 2 . \\ \sigma_{\mathrm{f}} & \text { fracture stress }\end{array}$

9. REFERENCES

[1] J. Merkle; An Examination of Size Effects and Data Scatter Observed in Small Specimen Cleavage Fracture Toughness Testing, NUREG/CR-3672, ORNL/TM-9088, (1984).

[2] R.O. Ritchie; A.W. Thompson; On Macroscopic and Microscopic Analysis for Crack Initiation and Crack Growth Toughness in Ductile Alloys, Metall. Trans., Vol. 15A, (1985), pp. 233-248.

[3] G.T. Hahn; The Influence on Microstructure on Brittle Fracture Toughness, Metall. Trans. Vol. 15A, (1984), pp. 947-959.

[4] C.J. McMahon, M. Cohen; Acta Metall., Vol. 3, (1965), pp. 591-604.

[5] P. Brozzo, G. Buzzichelli, A. Mascanzoni, M. Mirabile; Microstructure and Cleavage Resistance of Low Carbon Steel, Metal Science, Vol. 11, (1977), pp. 123-129.

[6] G. Irwin, Brittle-Ductile Transition Behavior in Reactor Vessel Steels, WRSI Meeting, NBS-Gaithersburg, Oct. (1986).

[7] D.A. Curry; Influence of Microstructure on Yield Stress and Cleavage Fracture Stress at $-196{ }^{\circ} \mathrm{C}$ of SA508 Class 2 Pressure Vessel Steel, Metal Science, Vol. 18 (1984), pp. 67-76.

[8] ASTM E813-81, Standard Method for J Ic, A Measure of Fracture Toughness, ASTM-Standards, Part 10, Metals, (1982).

[9] J.R. Griffiths; Dr. J. Owen, Journal of Mech. Phys. Solids, Vol. 19 (1971), pp. 491-431.

[10] J. Heerens, K.H. Schwalbe, A. Cornec; Modification of ASTM E 813 Standard Test Method for an Improved Definition of JIC Using a New Blunting Line Equation. Fracture Mechanics-18th Symposium, ASTM STP 945, edited by R.P. Reed and D.T. Read, American Society for Testing and Materials, Philadelphia, 1988, pp. 374-389. 
[11] D.M. Tracy; Finite Element Solution for Crack Tip Behavior in Small Scale Yielding, J. Eng. Maths. Tech., Vol. 98, (1976), pp. 146-151.

[12] J.R. Rice, M.A. Johnson; Inelastic Behavior of Solids, eds. M.F. Kanninen et al., McGraw-Hill, (1970), pp. 641-672.

[13] R.M. McMeeking; Finite Deformation Analysis of Crack Tip Opening in Elastic-Plastic Materials and Implication for Fracture. J. Mech. Solids, Vol. 25 (1977), pp. 375-381.

[14] K.H. Schwalbe; Comments to Finite Element Solution of Crack-Tip Behavior in Small Scale Yielding, Transactions of the ASME, April (1977), pp. $186-188$.

[15] J.R. Rice, C.F. Rosengren; J. Mech. Phys. Solids, Vol. 16 (1968), pp. $1-12$.

[16] C.F. Shih; Relationship Between the J-Integral and the Crack Tip Opening for Stationary and Extending Cracks, J. Mech. Phys. Solids, Vol. 29, (1981), pp. 305-326.

[17] A. Cornec, J. Heerens, K.H. Schwalbe, Bestimmung der RiBaufweitung CTOD und der Rissabstumpfung SZW und dem J-Integral, GKSS 86E15, (1985).

[18] H.G. DeLorenzi, F. Shih; 3D Elastic-Plastic Investigation of Fracture Parameters in Side Grooved Compact Specimens, Int. Journal of Fracture, Vol. 21, (1983), pp. 195-220.

[19] R.M. McMeeking, D.M. Parks; On the Criteria for J-Dominance of Crack-Tip Fields in Large Scale Yielding, Elast.-Plast. Fracture, ASTM STP 668 , (1979), pp. 175-194.

[20] E. Orowan, Rep. Progress Physics, Vol. 12, (1948), p. 185.

[21] D.A. Curry, J.F. Knott; Effects of Microstructure on Cleavage Fracture Stress in Steel, Metal Science. Vol. 12, (1978), pp. 511-514.

[22] F.C. Frank, A.W. Stroh, Proc. Phys. Soc., Vol. 65B, (1952), p. 811.

[23] G.T. Hahn, B.L. Auerbach, W.S. Owen, M. Cohen; Fracture, B.L. Averbach et al., eds. John Wiley and Sons, New York, (1959), p. 91.

[24] R.0. Ritchie, J.F. Knott, J.F. Rice; On the Relationship Between Critical Tensile Stress and Fracture Toughness in Mild Steels. J. Mech. Phys.

Solids, Vol. 21, (1973), pp. 395-410.

[25] J. Watanabe, T. Iwadate, Y. Tanaka, T. Yokobori, K. Ando; Fracture Toughness in the Transition Region, to be published in J. of Frac, Mech. Nov. 1987. 


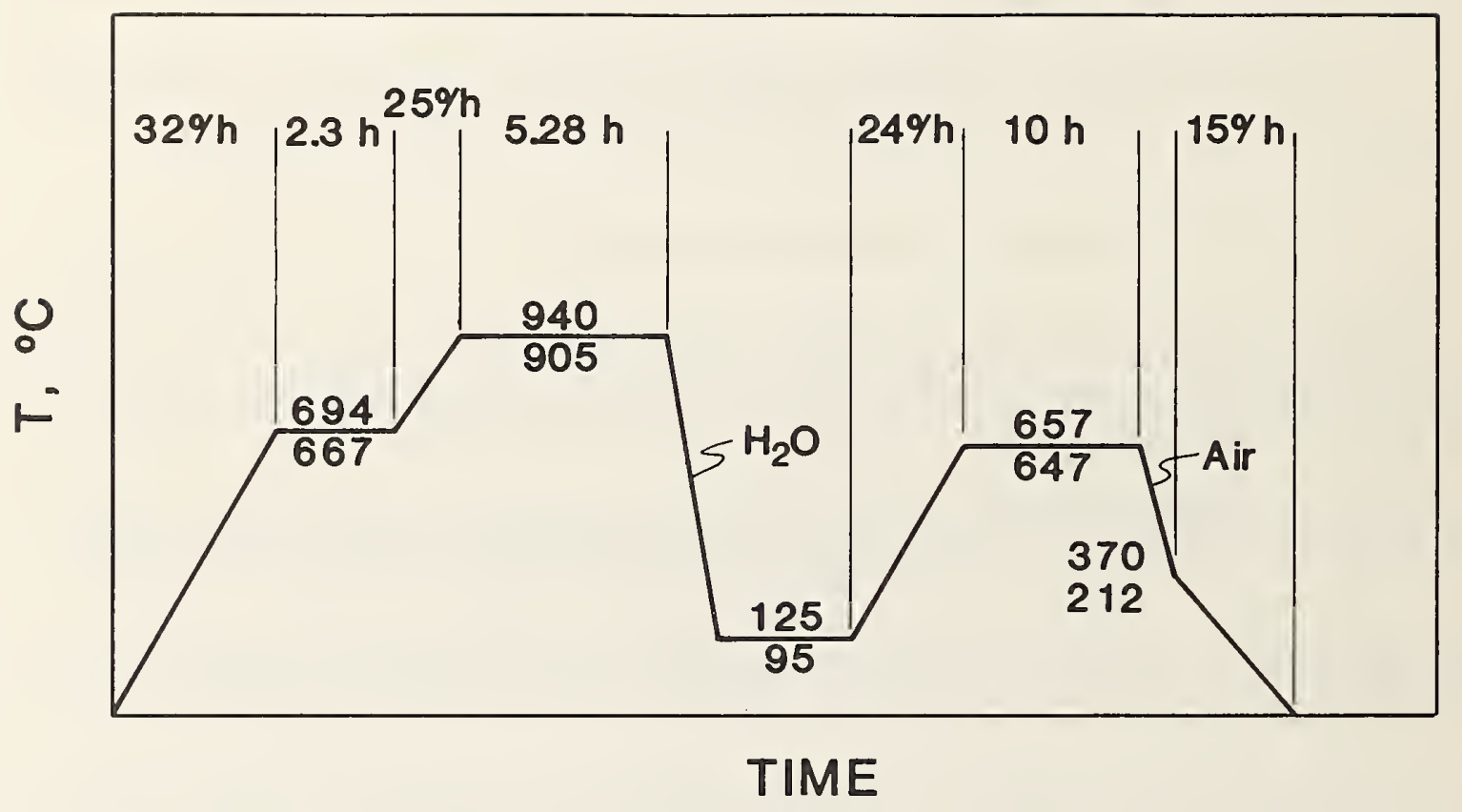

Figure 1. Heat treatment of the forged material. 

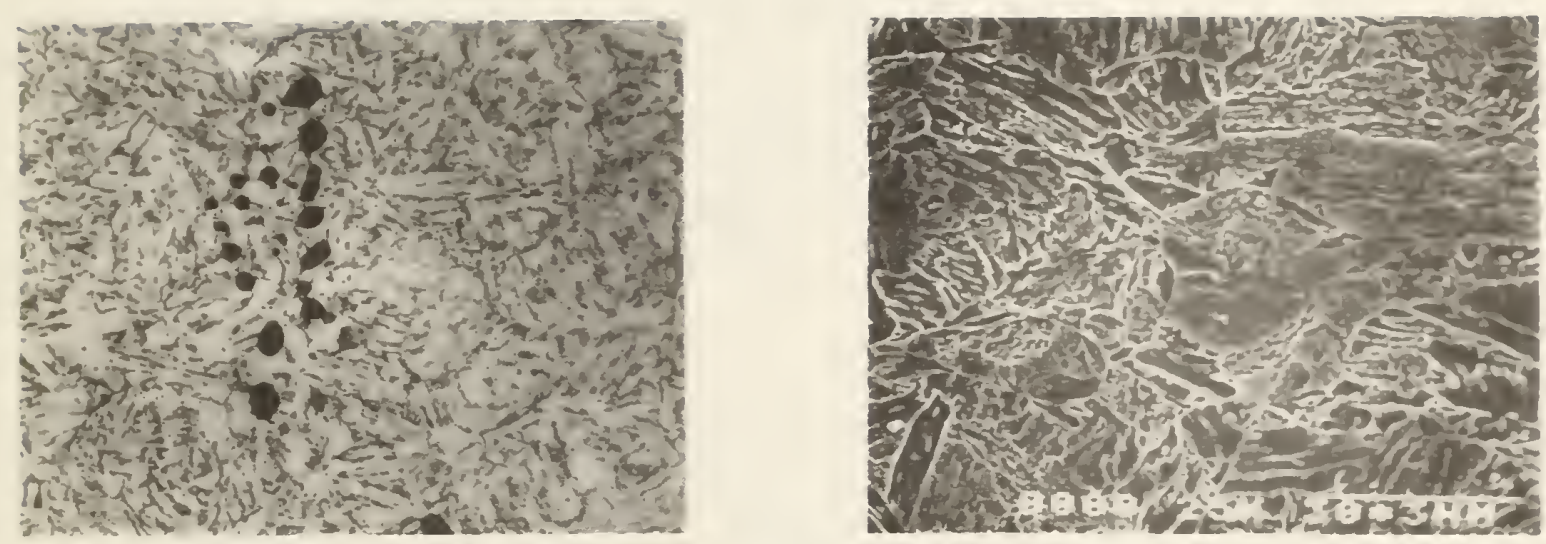

Figure 2. Microstructure of the material.

a. cluster of large inclusions

b. small carbides are arranged in rows within the ferrite grains 


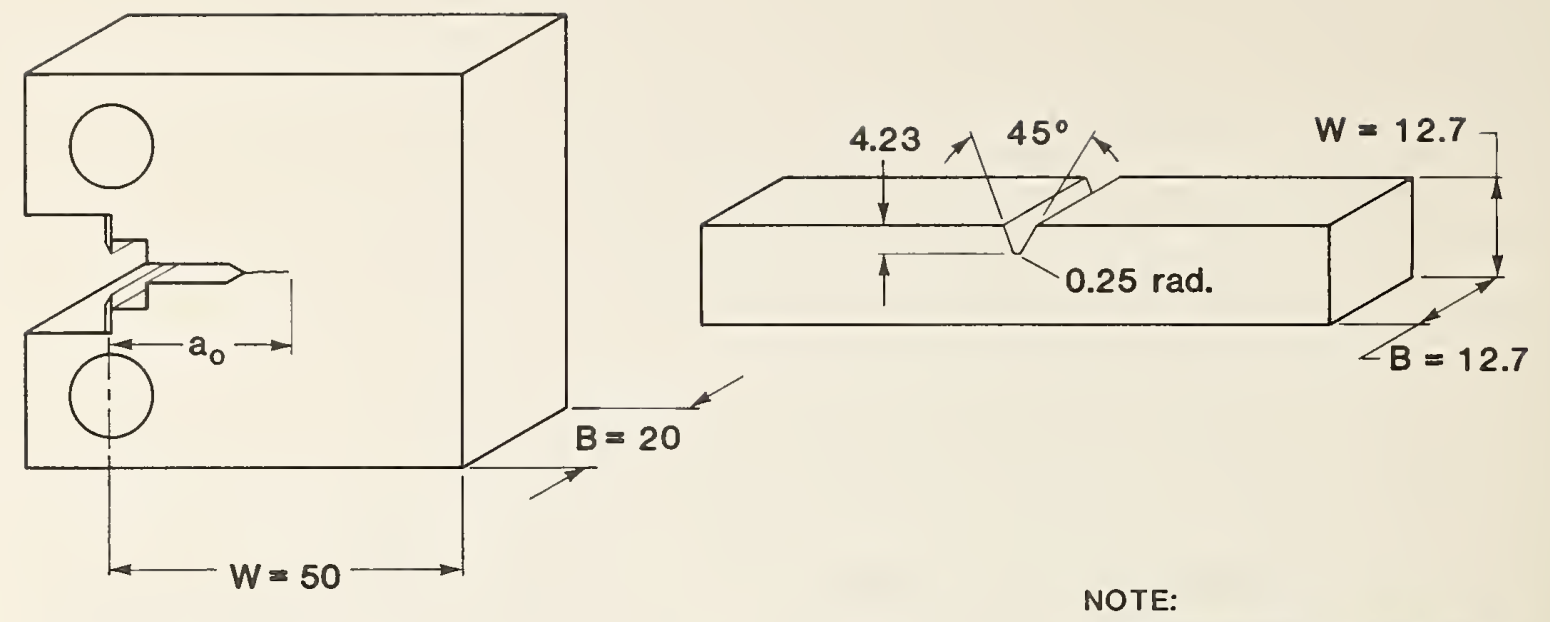

All dimensions in millimeters

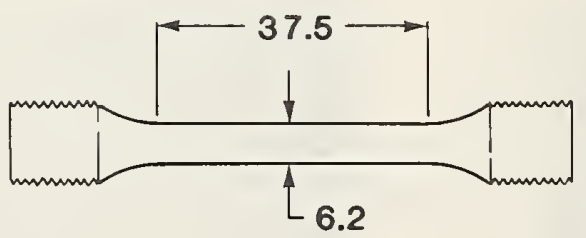

Figure 3. CT-specimens, blunt notched bend bars and tensile specimens as used in this study.

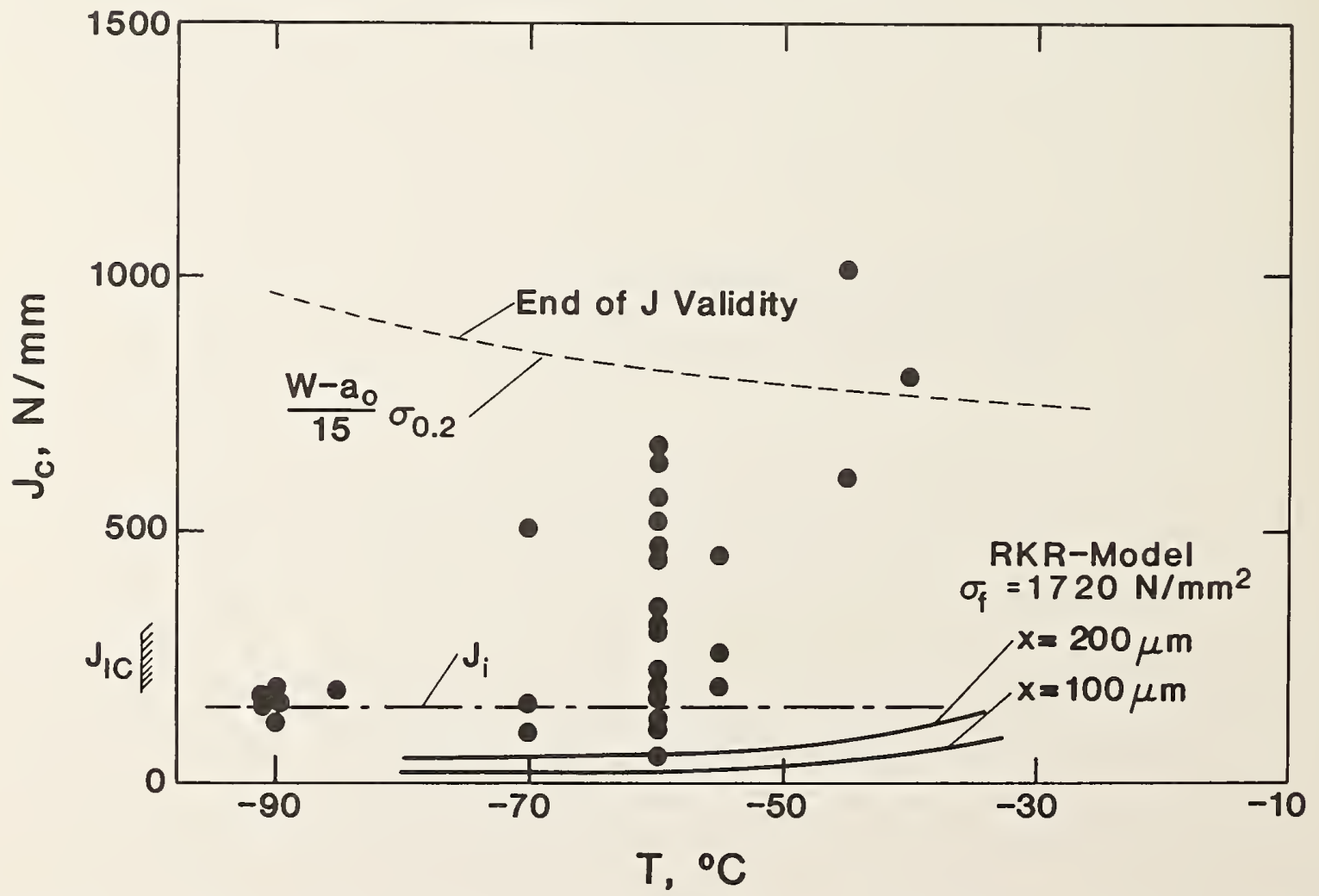

Figure 4. Fracture toughness of the material in the upper transition region. 


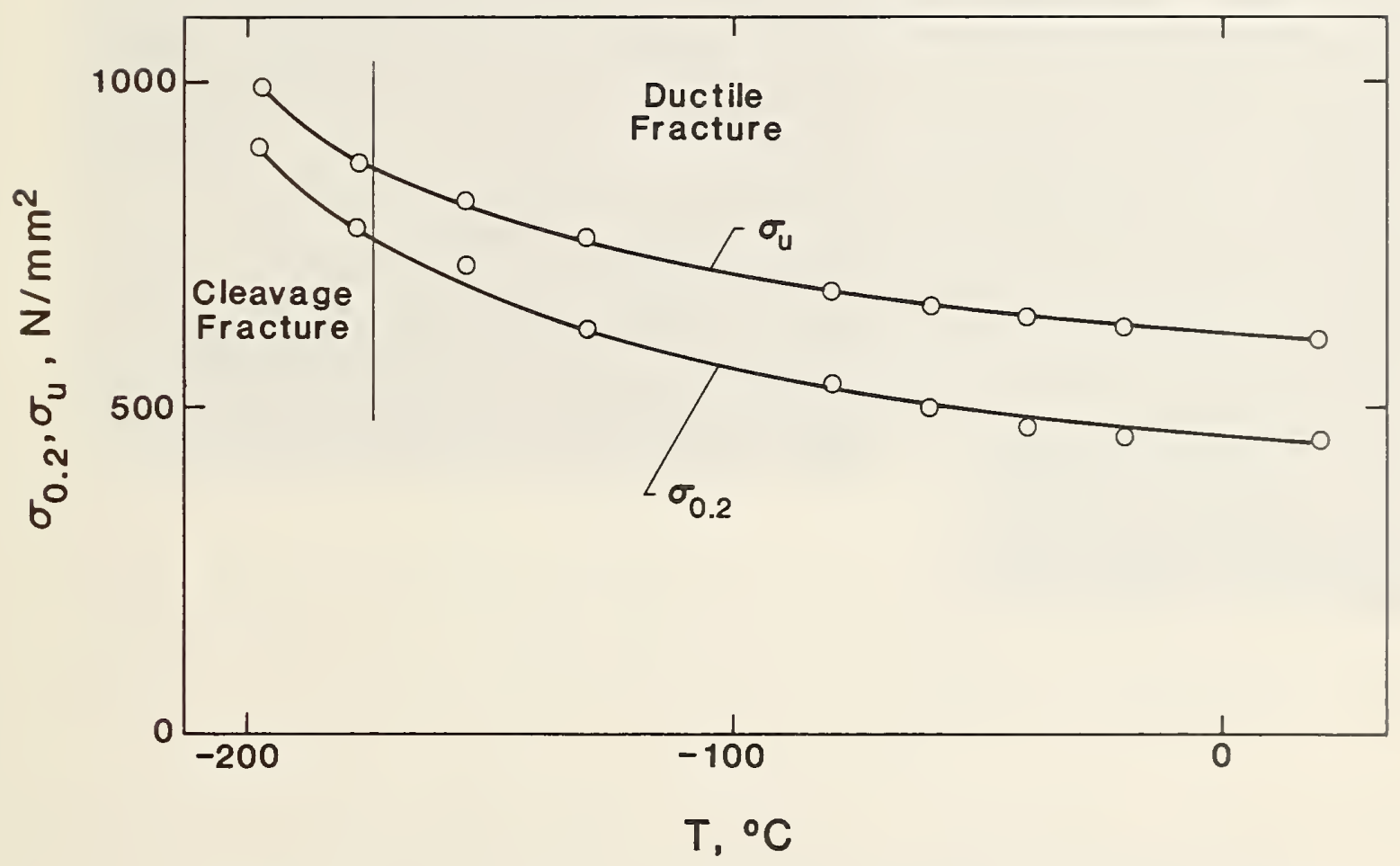

Figure 5. Ultimate tensile strength and yield strength versus temperature 

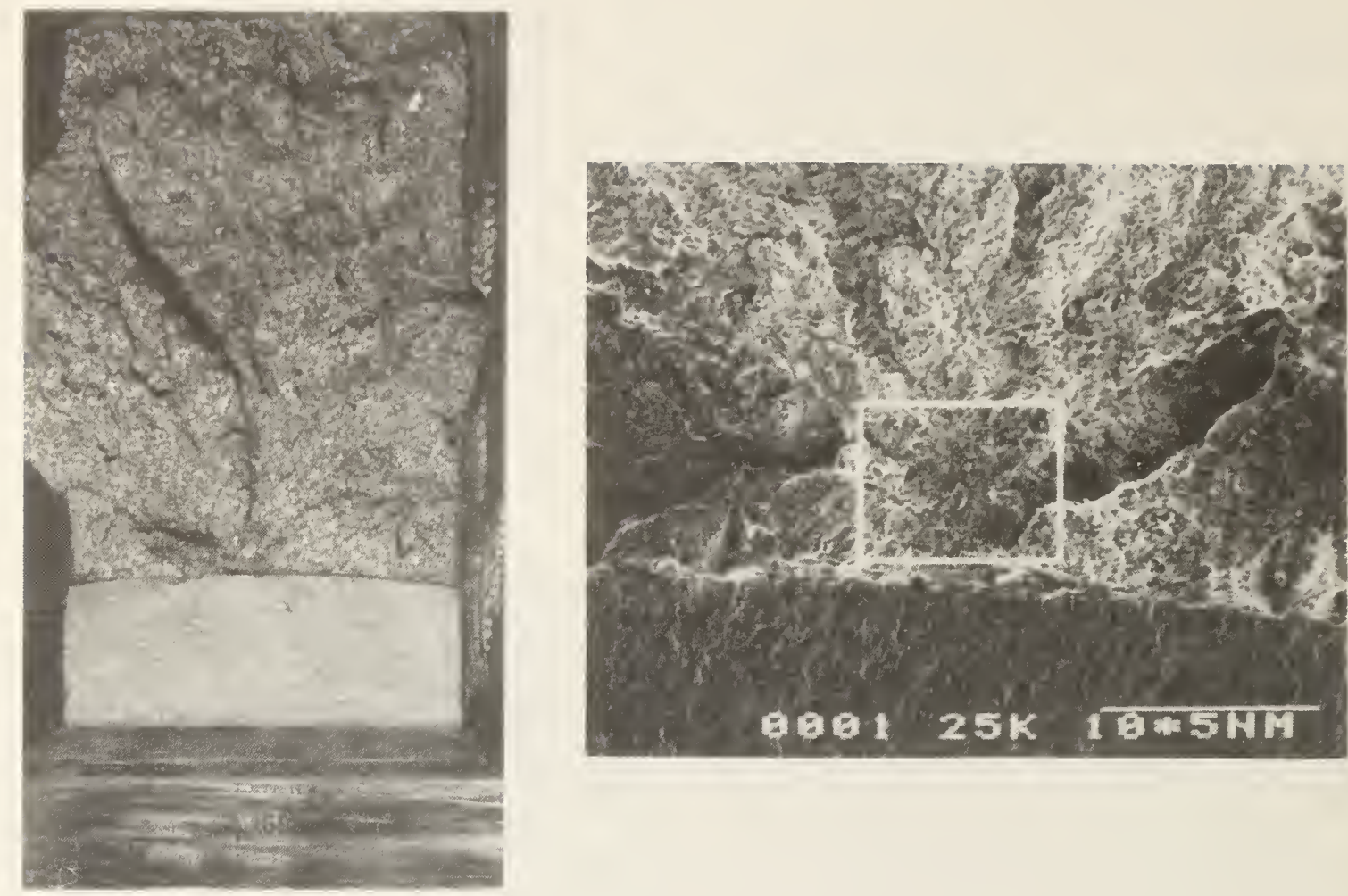

\section{$20 \mathrm{~mm}$}

Figure 6. Fracture surface of a CT-specimen showing macroscopic river pattern which emanates from one small area on the fracture surface in front of the fatigue crack tip.
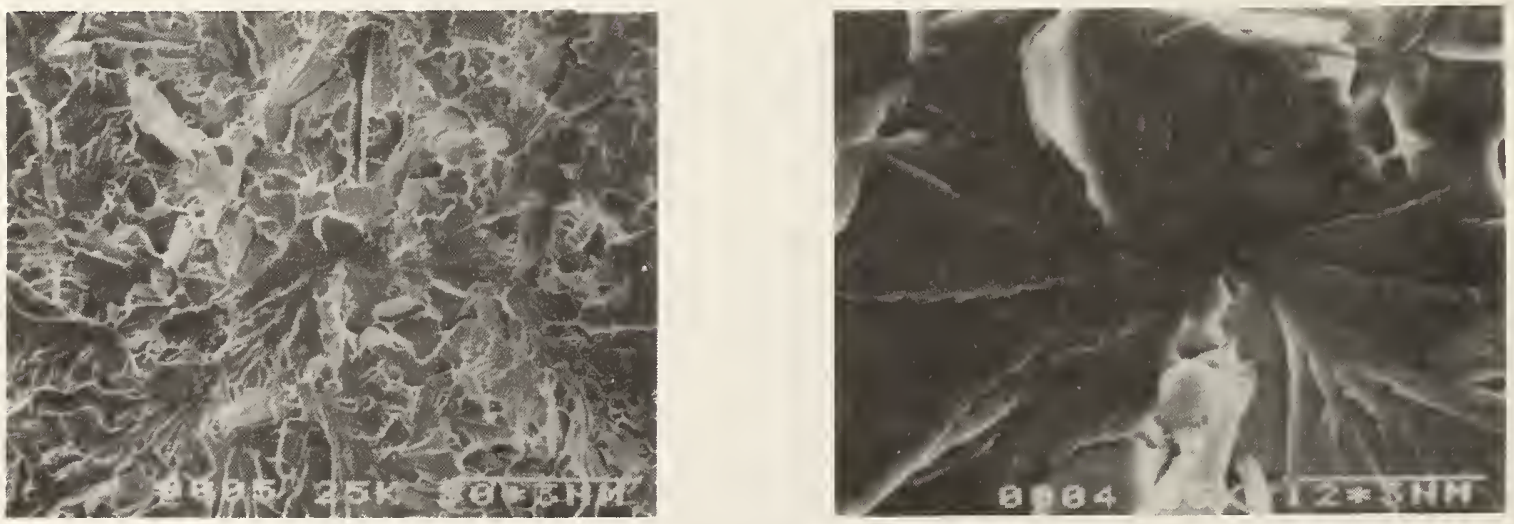

Figure 7. Cleavage fracture surface showing fine river pattern. A single cleavage facet is located at the center of the river pattern. 

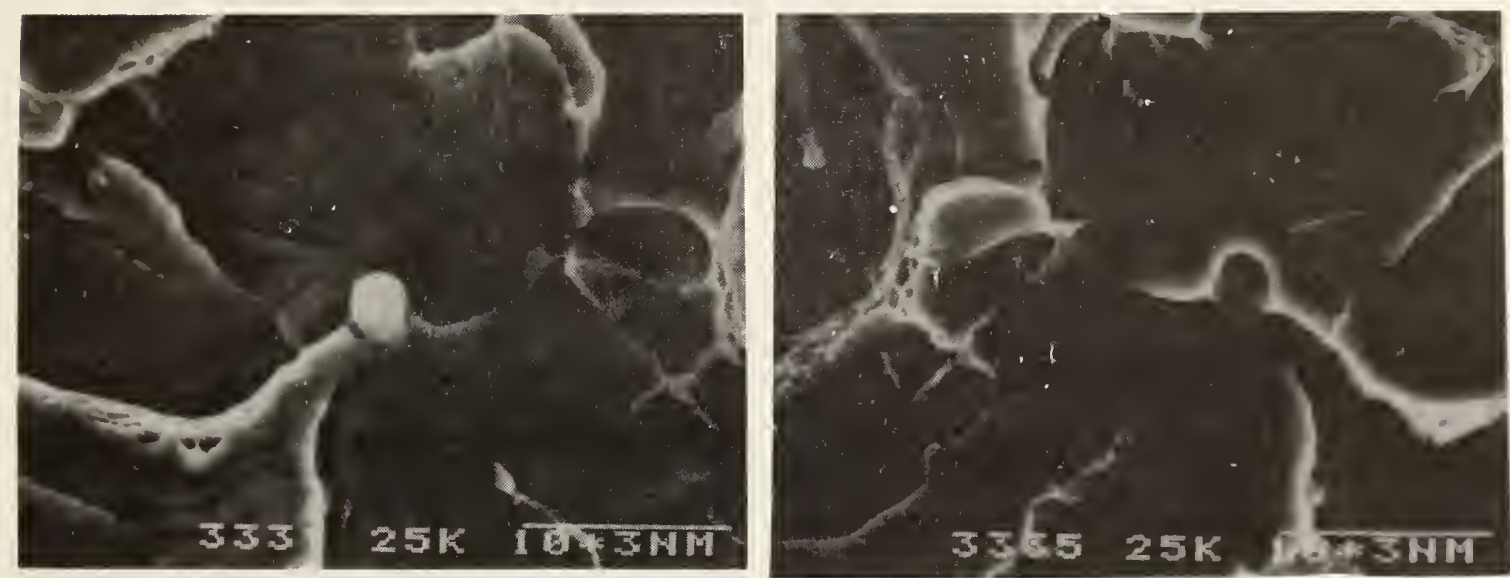

$10 \mu \mathrm{m}$

Figure 8. A nonfractured inclusion at the center of the river pattern. Both fracture surfaces of a CT-specimen are shown. 


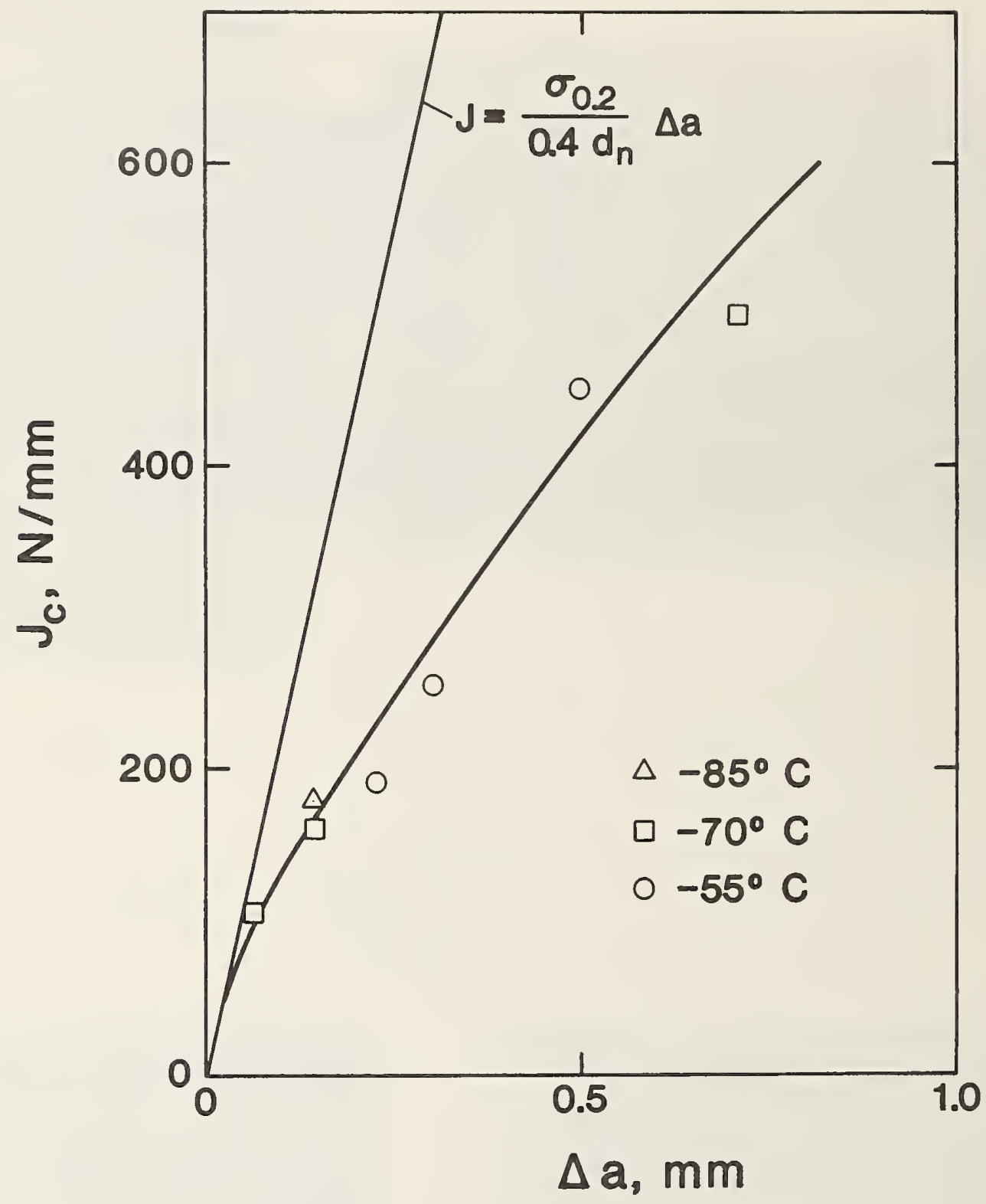

Figure 9. J- $\Delta$ a curve of the CT-specimens within the temperature range of -55 to $-85{ }^{\circ} \mathrm{C}$. Each data point indicates one specimen. The blunting line was calculated as proposed in [17]. 

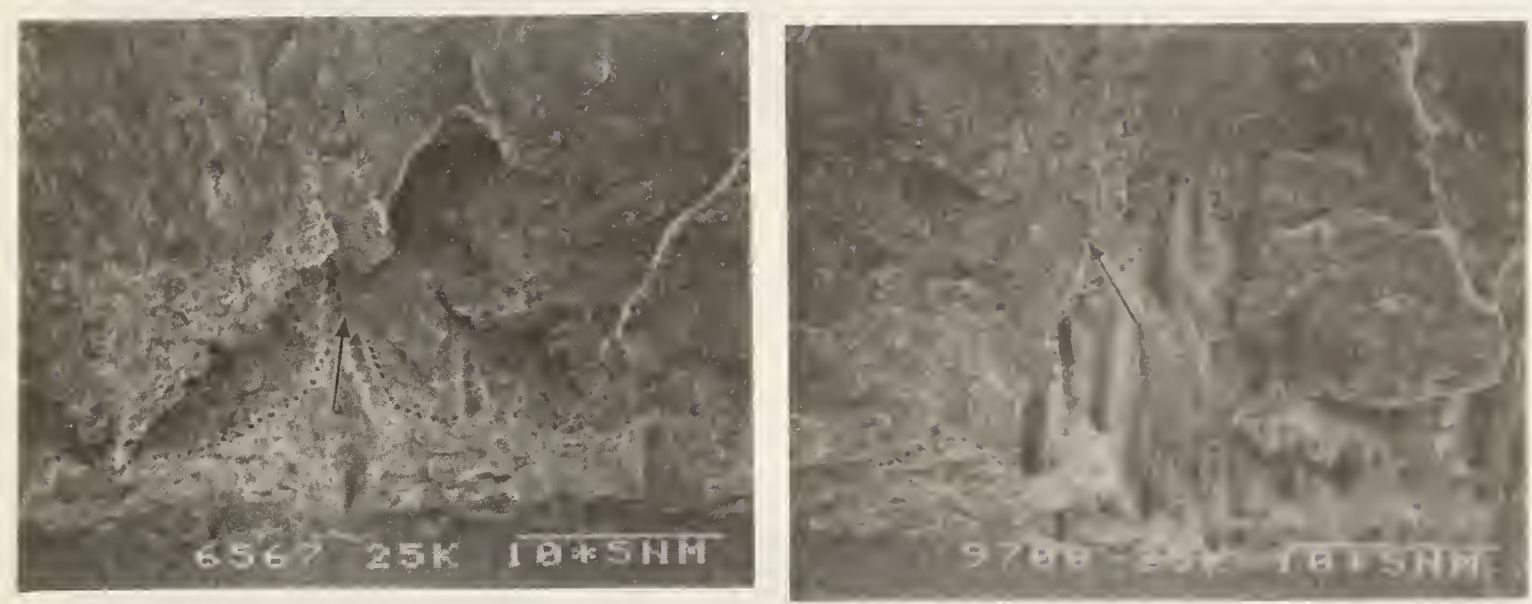

Figure 10. Cleavage fracture initiation at a local zone of ductile tearing. Two different CT-specimens are shown. 

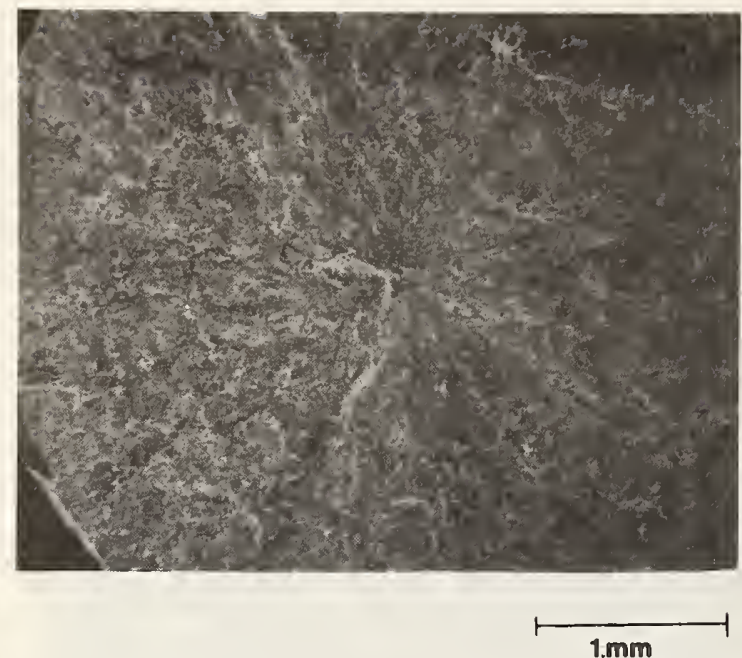

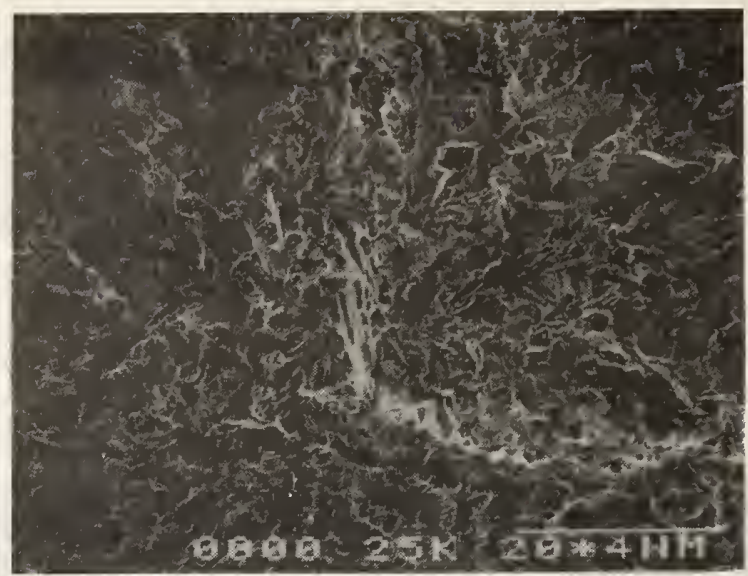

$200 \mu \mathrm{m}$

Figure 11a. Macroscopic river pattern of a tensile specimen, tested at $-196{ }^{\circ} \mathrm{C}$.

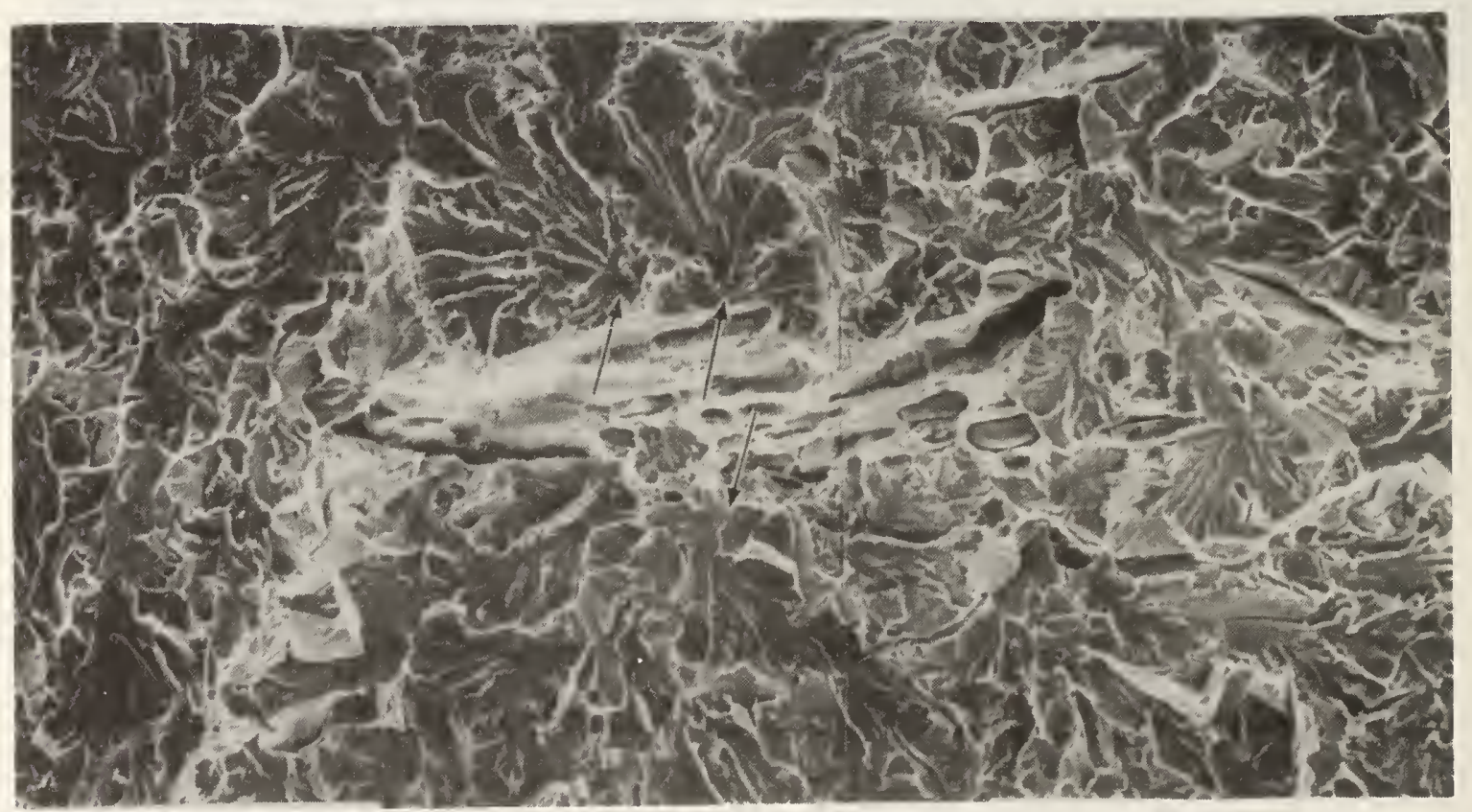

Figure 11b. Cluster of large inclusions in the center of the river pattern; a number of single cleavage initiation sites form the center of the fine pattern at the border of the cluster. 


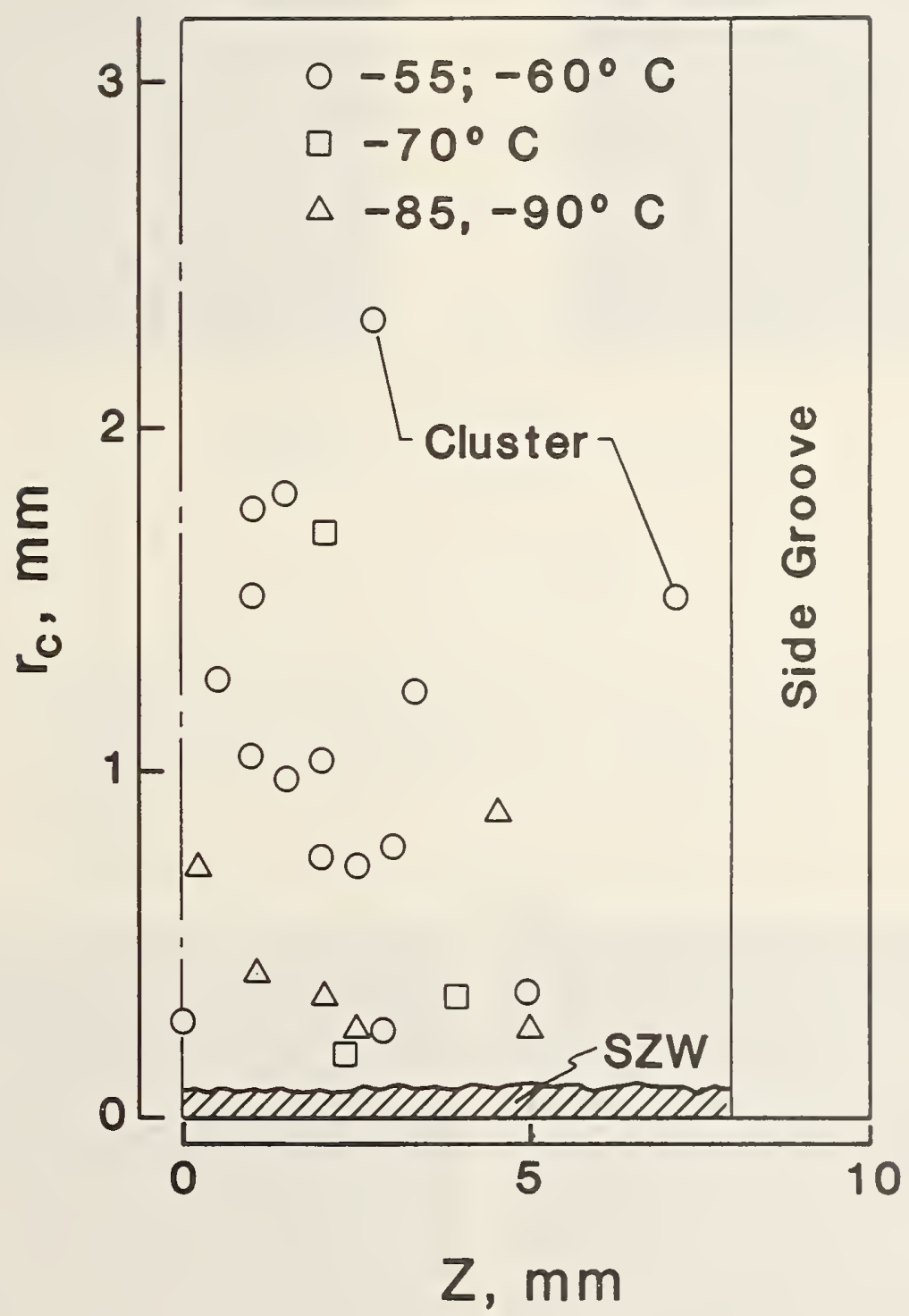

Figure 12. Location of the cleavage initiation site in the ligament. (Each data point indicates one test.) 

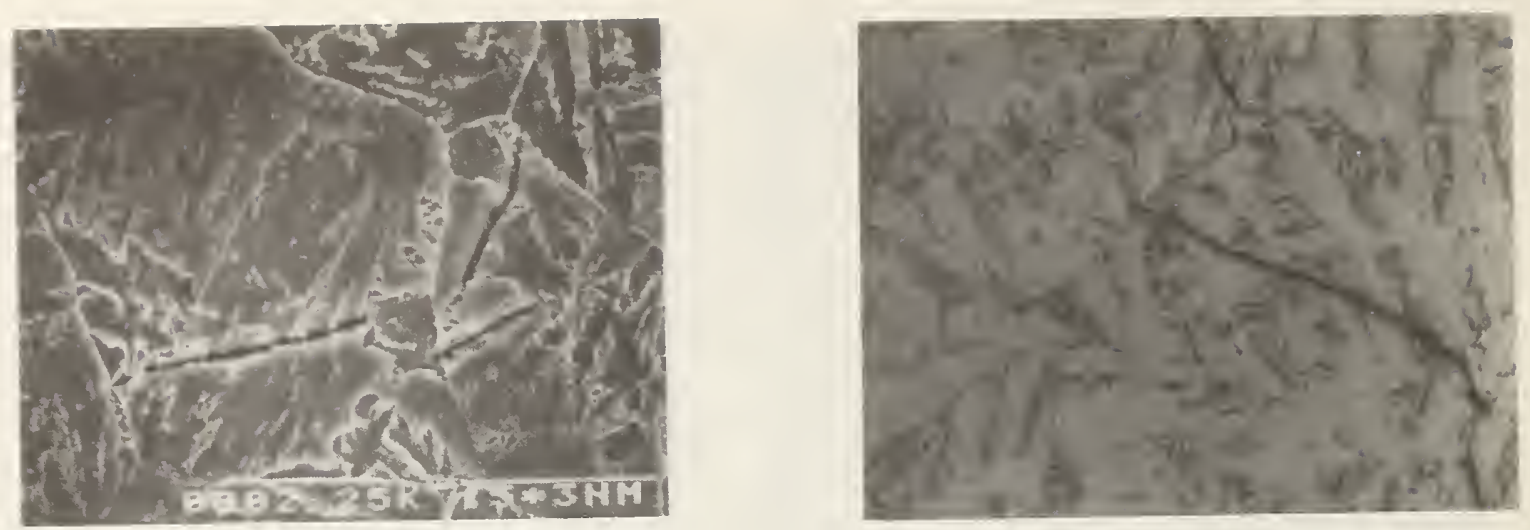

Figure 13. Cleavage microcracks which become arrested or deflected at the grain boundaries. (The micrograph was taken at a distance of 200 $\mu \mathrm{m}$ to $300 \mu \mathrm{m}$ ahead of the fatigue crack tip.)
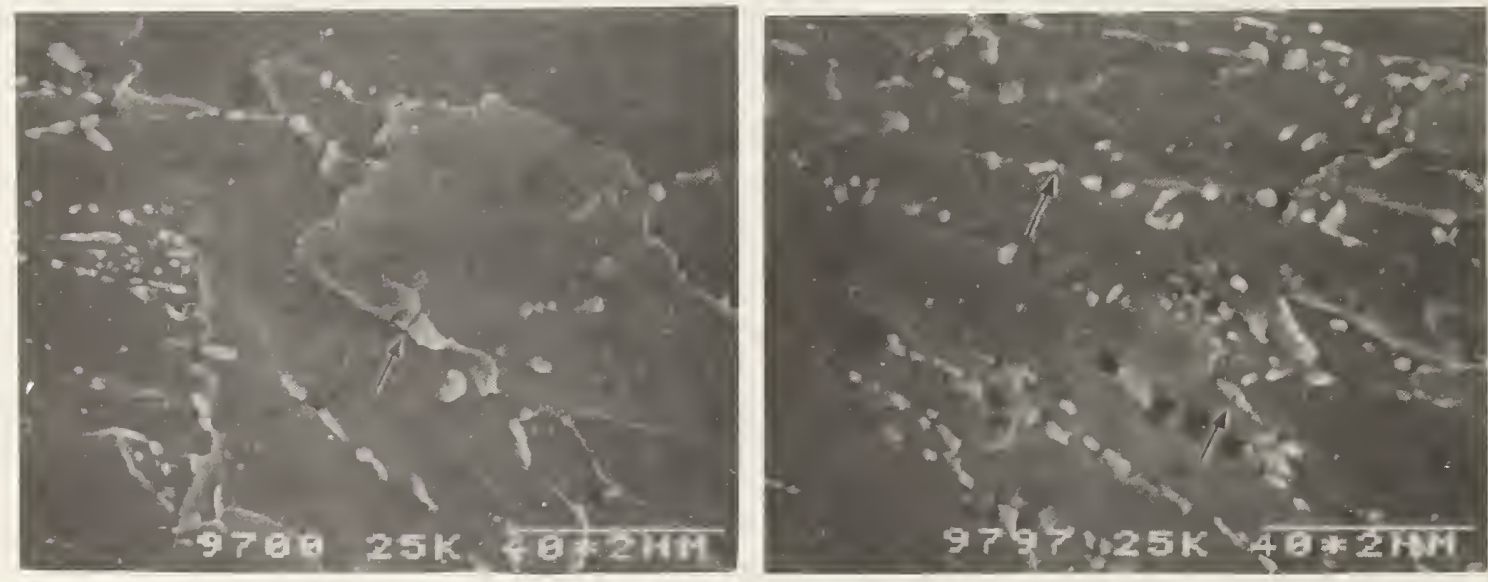

$\longmapsto$

Figure 14. Fractured carbide particles in a tensile specimen tested at $-196{ }^{\circ} \mathrm{C}$. The plastic strain is about 10 to 15 percent. 


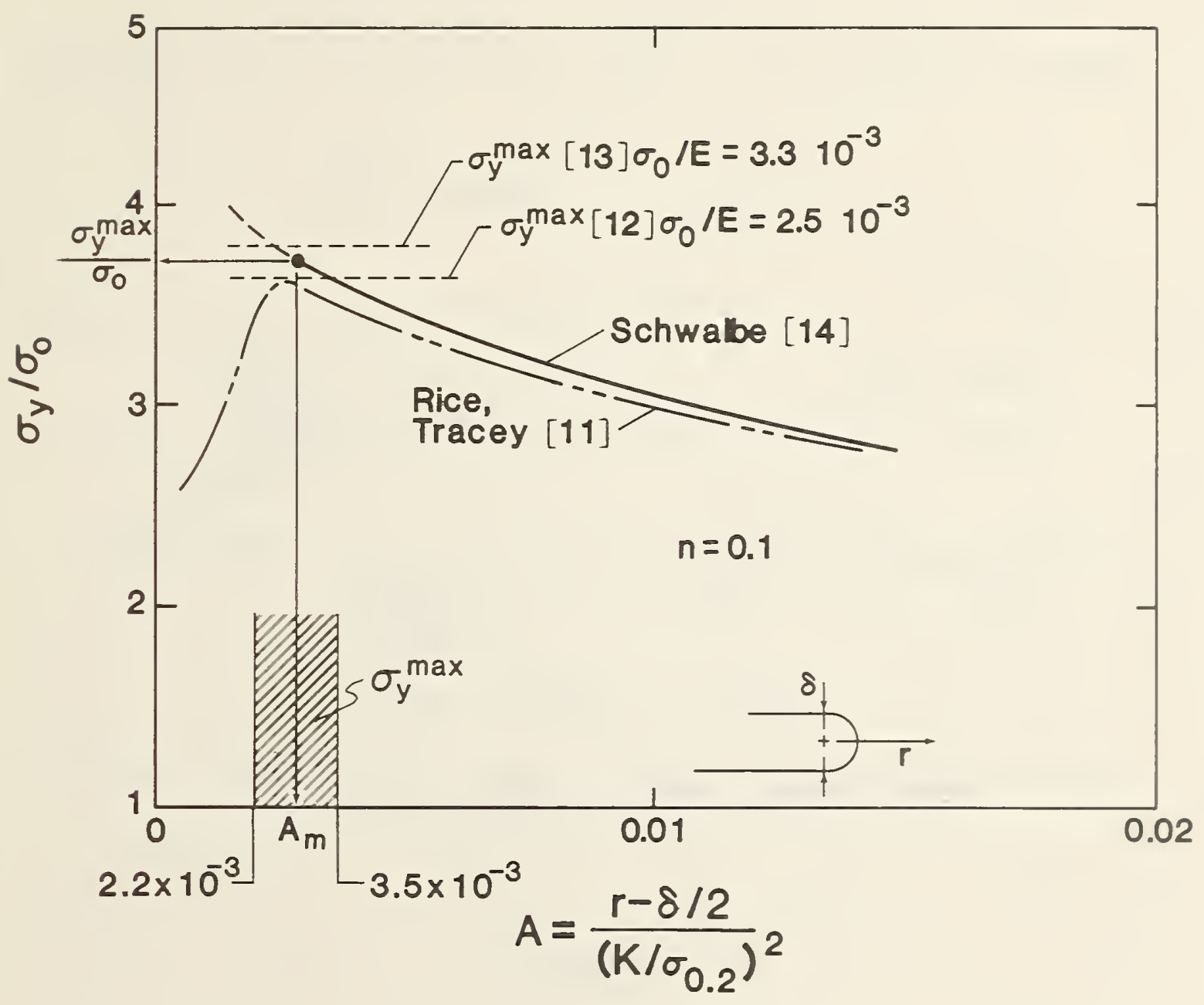

Figure 15. Normal stresses in front of a blunted crack tip. The solution in [14] was used in this study. 


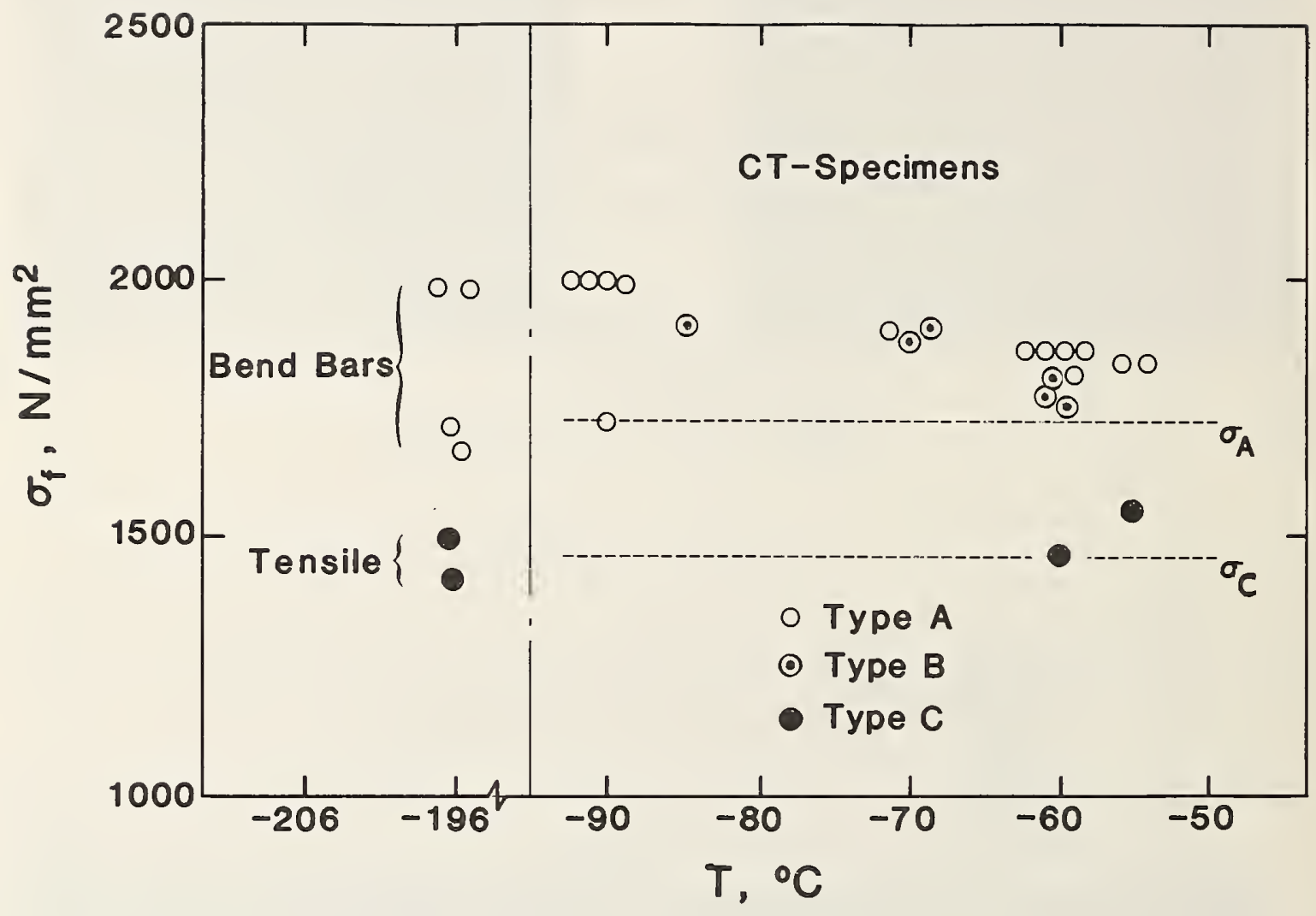

Figure 16. Fracture stresses of the various specimens for the various types of initiation sites. 


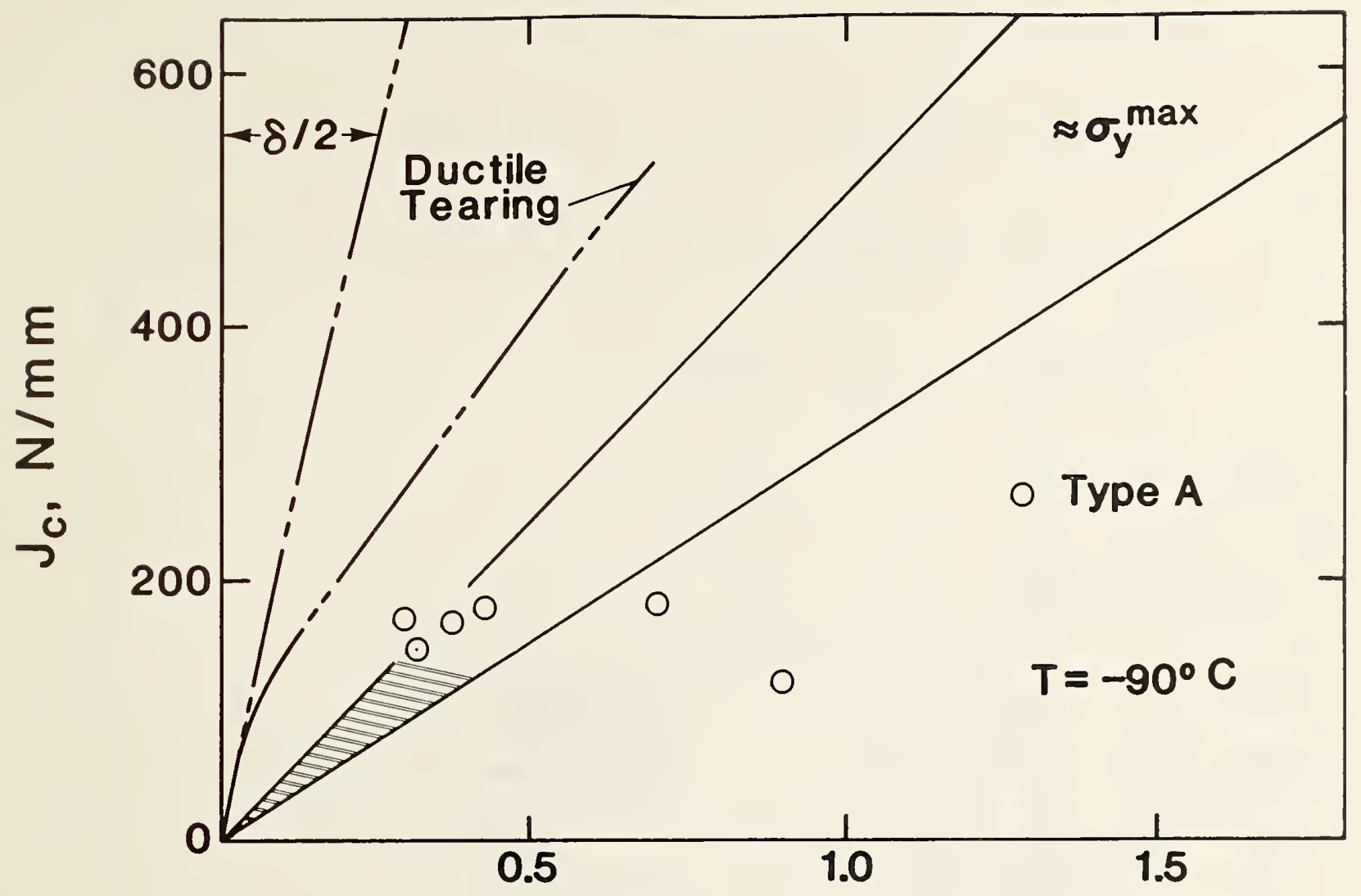

\section{$\Delta a, r_{c}, m m$}

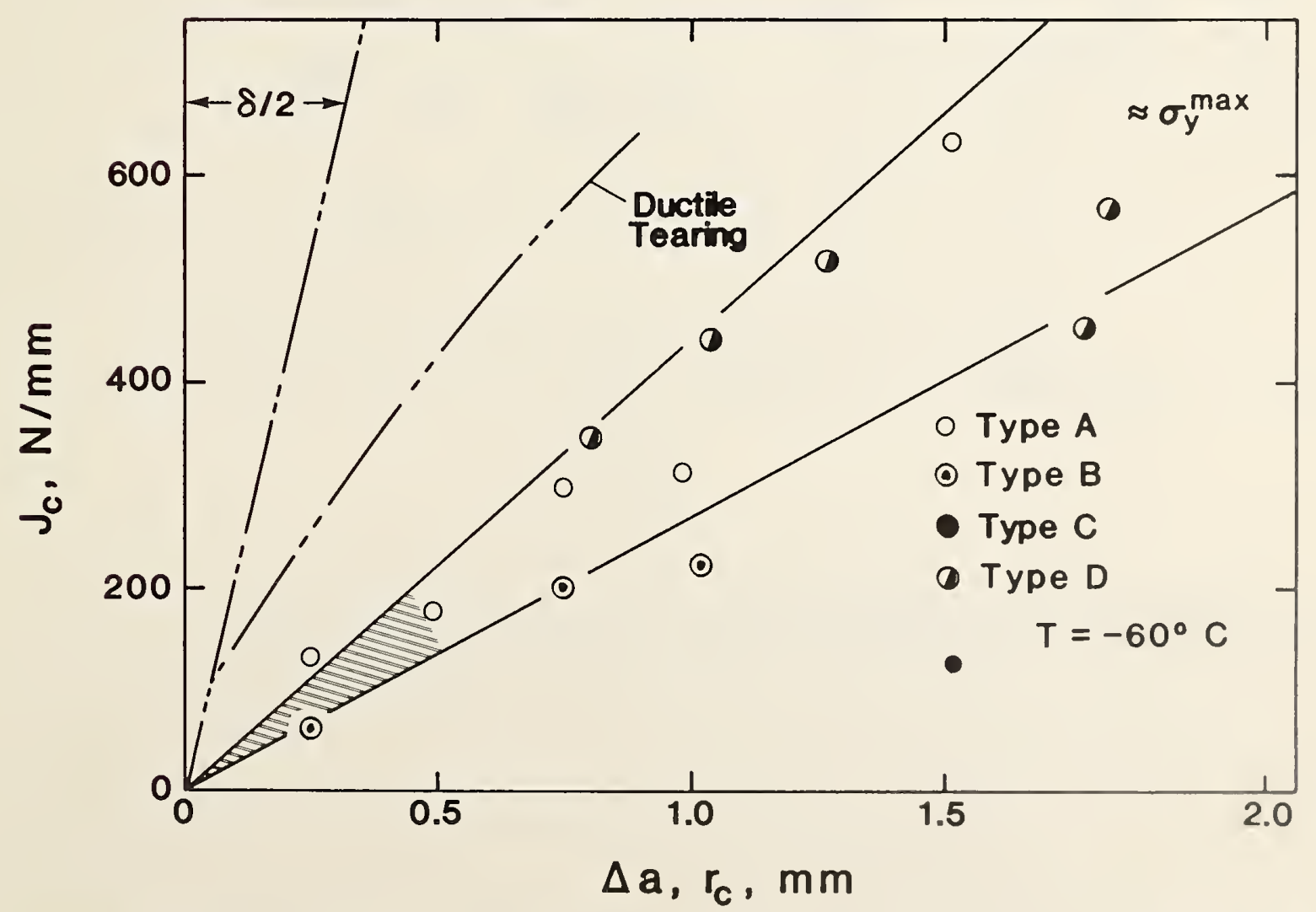

Figure 17. Relationship between the location of the initiation sites and the value of fracture toughness. Lines indicate the approximate location of the normal stress peak in front of the crack tip. 


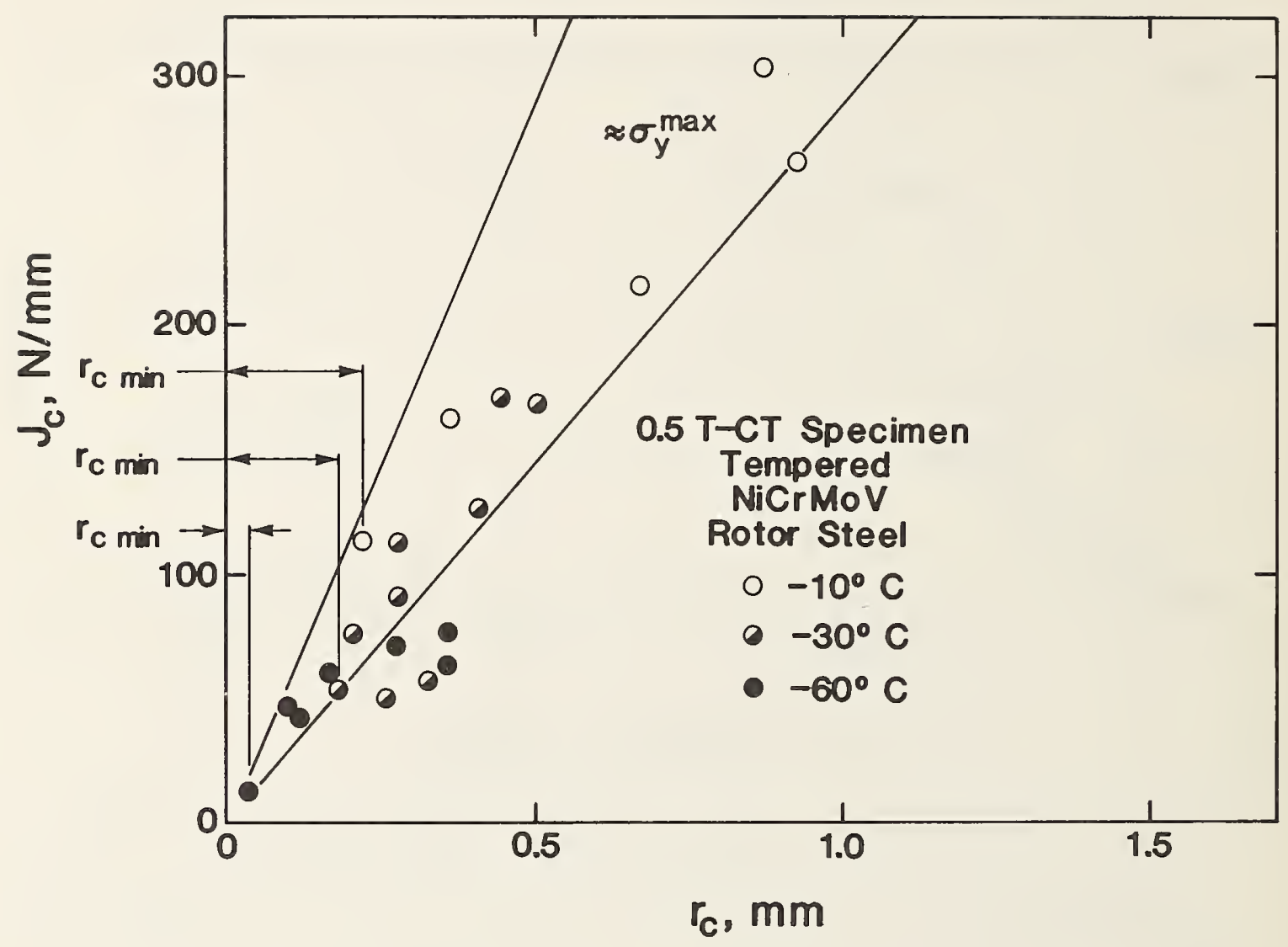

Figure 18. The $r_{m i n}$-value for different temperatures (data were taken from [25]). 


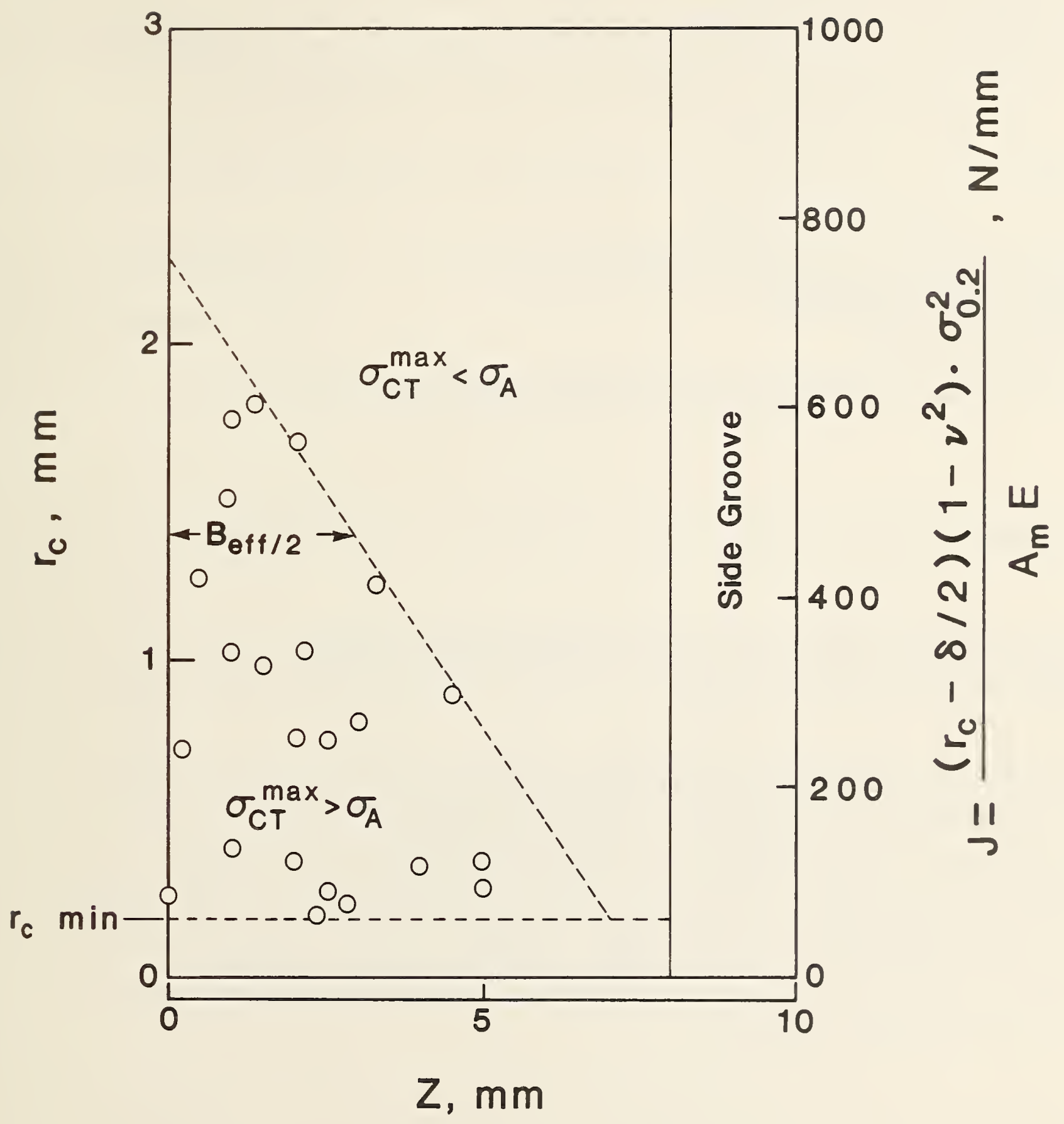

Figure 19. Relationship between effective thickness Beff and J-integral, as indicated by the locations of the cleavage initiation sites found in this study. 
NBS-114A IREV. $2.8 \mathrm{C}$

U.S. DEPT. OF COMM.

BIBLIOGRAPHIC DATA

SHEET (See in structions)
1. PUBLICATION OR REPORT NO.

NISTIR $88-3099$
2. Performing Organ. Report No.

3. Publication Date

December 1988

4. TITLE AND SUBTITLE

Fracture Behavior of a Pressure Vessel Steel in the Ductile to

Brittle Transition Region

5. AUTHOR(S)

J. Heerens, D.T. Read

6. PERFORMING ORGANIZATION (If joint or other than NBS, see instructions)

National Institute of Standards and Technology

NAFINAL-BUREAU-OF-SFANBAROS

DEPARTMENT OF COMMERCE

WASHINGTON, D.C. 20234

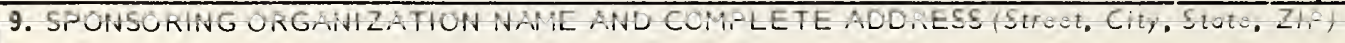

7. Contract/Grant No.

8. Type of Report \& Period Covered

10. SUPPLEMENTARY NOTES

Document describes a computer program; SF-185, FIPS Software Summary, is attached.

11. ABSTRACT (A 200-word or less factual summary of most significant information. If document includes a significant bitliography or literature survey. mention it here)

The reasons for the scatter of fracture toughness in the ductile-to-brittle transition region, as well as the mechanisms leading to cleavage fracture, have been investigated for a quenched and tempered pressure vessel steel, DIN 20 MnMoNi 55. The iracture surfaces indicate that cleavage fracture starts at one small area in the ligament, the cleavage initiation site. Cleavage initiation occurs ahead of the crack tip at the location of the maximum normal stresses. Fractography and metallography show four different types of initiation sites. The mechanisms which may trigger cleavage fracture at these initiation sites are discussed. The results indicate that the scatter of fracture toughness is due to the scatter in the distance between the cleavage initiation site and the fatigue crack tip.

12. KEY WORDS (Six to twelve entries; alphabetical order; capitalize only proper names; and separate key words by semicolons) cleavage; fracture stress; inclusions; initiation site; mechanism; origin; scatter; weak 1 ink

\section{AVAILABILITY}

XX Unlimited

[ For Official Distribution. Do Not Release to NTIS

$\square$ Order From Superintendent of Documents, U.S. Government Printing Office, Washington, D.C. 20402.
14. NO. OF PRINTED PAGES

44

15. Price

XX Order From National Technical Information Service (NTIS), Springfield, VA. 22I6I 


. 


$\sigma$ 